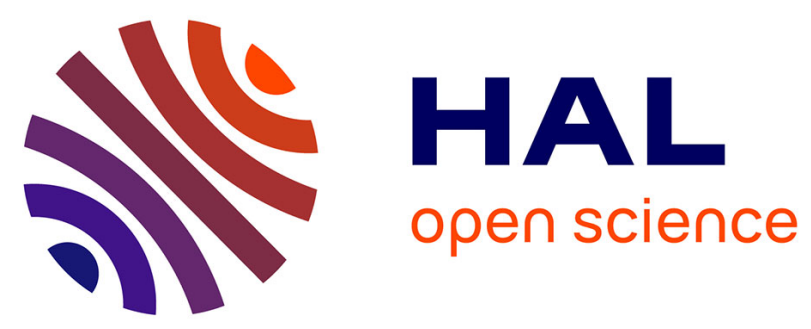

\title{
On competitive nonlinear pricing
}

Andrea Attar, Thomas Mariotti, Francois Salanie

\section{To cite this version:}

Andrea Attar, Thomas Mariotti, Francois Salanie. On competitive nonlinear pricing. Theoretical Economics, 2019, 14 (1), pp.297-343. 10.3982/TE2708 . hal-02097209

\section{HAL Id: hal-02097209 \\ https://hal.science/hal-02097209}

Submitted on 26 May 2020

HAL is a multi-disciplinary open access archive for the deposit and dissemination of scientific research documents, whether they are published or not. The documents may come from teaching and research institutions in France or abroad, or from public or private research centers.
L'archive ouverte pluridisciplinaire HAL, est destinée au dépôt et à la diffusion de documents scientifiques de niveau recherche, publiés ou non, émanant des établissements d'enseignement et de recherche français ou étrangers, des laboratoires publics ou privés.

\section{다)(1) $(5$}

Distributed under a Creative Commons Attribution - NonCommercial| 4.0 International 


\title{
On competitive nonlinear pricing
}

\author{
Andrea Attar \\ Toulouse School of Economics, CNRS, University of Toulouse Capitole and Dipartimento di Economia e \\ Finanza, Università degli Studi di Roma“Tor Vergata”
}

Thomas Mariotti

Toulouse School of Economics, CNRS, University of Toulouse Capitole

François SALANiÉ

Toulouse School of Economics, INRA, University of Toulouse Capitole

\begin{abstract}
We study a discriminatory limit-order book in which market makers compete in nonlinear tariffs to serve a privately informed insider. Our model allows for general nonparametric specifications of preferences and arbitrary discrete distributions for the insider's private information. Adverse selection severely restricts equilibrium outcomes: in any pure-strategy equilibrium with convex tariffs, pricing must be linear and at most one type can trade, leading to an extreme form of market breakdown. As a result, such equilibria exist only under exceptional circumstances that we fully characterize. These results are strikingly different from those of existing analyses that postulate a continuum of types. The two approaches can be reconciled when we consider $\varepsilon$-equilibria of games with a large number of market makers or a large number of types.
\end{abstract}

Keywords. Adverse selection, competing mechanisms, limit-order book.

JEL Classification. D43, D82, D86.

Andrea Attar: andrea. attar@tse-fr.eu

Thomas Mariotti: thomas .mariotti16@gmail.com

François Salanié: francois.salanie@inra.fr

We thank the editor and three anonymous referees for very thoughtful and detailed comments. We also thank Bruno Biais, Pradeep Dubey, Srihari Govindan, Martin Hellwig, Richard Kihlstrom, John Hardman Moore, Alessandro Pavan, Jean-Charles Rochet, Dimitri Vayanos, and Michael Whinston for extremely valuable feedback. Finally, we thank seminar audiences at Aalto School of Economics, Chinese Academy of Sciences, ETH Zürich, Harvard-MIT Theory Workshop, LSE, Max-Planck-Institut zur Erforschung von Gemeinschaftsgütern, Northwestern University, Toulouse School of Economics, Università degli Studi di Milano-Bicocca, Université de Montpellier, and Wharton School, as well as conference participants at the 2013 Cowles Foundation Annual Conference on General Equilibrium and its Applications, the 2013 ENSAI Economic Day, the 2013 Glasgow SIRE Workshop in Microeconomic Theory, the 2013 LUISS Workshop on Macroeconomics and Financial Frictions, the 2013 SAET Conference, the 2013 Université Paris-Dauphine Workshop in Honor of Rose-Anne Dana, the 2014 European Meeting of the Econometric Society, the 2014 IDEI Conference on Trading in Electronic Markets, the 2014 International Conference on Game Theory, and the 2014 Sciences Po Summer Workshop in International Finance and Macro Finance for many useful discussions. Elena Panova provided excellent research assistance. Financial support from the Chaire Marchés des Risques et Création de Valeur and the European Research Council (Starting Grant 203929-ACAP) is gratefully acknowledged.

(C) 2019 The Authors. Licensed under the Creative Commons Attribution-NonCommercial License 4.0. Available at http://econtheory.org. https://doi.org/10.3982/TE2708 


\section{InTRODUCTION}

Important financial markets, such as EURONEXT or NASDAQ, rely on a discriminatory limit-order book to balance supply and demand. The book gathers the limit orders placed by market makers; each limit order allows one to buy or sell at a prespecified price any volume of shares up to a prespecified limit. Any upcoming order is matched with the best offers available in the book. Pricing is discriminatory, in the sense that each market maker is paid according to the price he quoted for a given volume of shares. This paper contributes to the study of price formation in limit-order markets.

An important obstacle to trade on such markets is that market makers may face an insider with superior information about the value of the traded asset. This makes them reluctant to sell, as they suspect that this value is likely to be high when the asset is in high demand. To alleviate adverse selection, market makers can place collections of limit orders or, equivalently, post tariffs that are convex in the traded volume. The insider then hits the resulting limit-order book with a market order that reflects her private information, paying a higher price at the margin for a higher volume of shares. The problem of price formation thus amounts to characterizing the tariffs posted by market makers in anticipation of the insider's trading strategy.

In an influential article, Biais et al. (2000) tackle this problem in a model where strategic market makers face a risk-averse insider who has private but imperfect information about the value of an asset, and, thus, has both informational and hedging motives for trade. Assuming that the insider's valuation for the asset has a continuous distribution, they exhibit a symmetric pure-strategy equilibrium in which market makers post strictly convex tariffs that may be interpreted as infinite collections of infinitesimal limit orders. Market makers earn strictly positive expected profits in equilibrium. Back and Baruch (2013) consider a slightly different game in which market makers are restricted to posting convex tariffs. Using a different method, they identify the same symmetric equilibrium tariffs as Biais et al. (2000).

In contrast to these results, Attar et al. (2014) argue that strategic competition between uninformed market makers may cause a breakdown of discriminatory markets. To make this point, they consider a general model of trade in which several sellers compete in menus of contracts to serve a buyer whose private information, or type, has a binary distribution. In this context, they show that in any pure-strategy equilibrium, one type can trade only if the other type is driven out of the market, an outcome reminiscent of Akerlof (1970). Each seller earns zero expected profit in equilibrium, and equilibria can be sustained by linear tariffs. A pure-strategy equilibrium fails to exist whenever the two buyer's types have sufficiently close preferences.

The heterogeneity of these findings constitutes a puzzle: the equilibrium predictions of competitive nonlinear-pricing models seem to dramatically depend on the assumptions made on the distribution of the insider's private information. A natural question is whether there is something special about the continuous-type case or the two-type case that would explain their contrasting implications. The objective of this paper is to clarify the origin of this puzzle and to outline possible solutions.

To this end, we set up a general model of the discriminatory limit-order book allowing for nonparametric specifications of preferences and arbitrary discrete distributions 
for the insider's type. We exploit the richness of this framework, which embeds the twotype model of Attar et al. (2014) as a special case, to investigate the extent to which trade takes place in equilibrium when the number of types grows large. To capture the functioning of a discriminatory limit-order book, we focus on equilibria in which market makers post convex tariffs, which can be interpreted as collections of limit orders. As for deviations, we consider two scenarios. In the arbitrary-tariff game, market makers can post arbitrary tariffs, as in Biais et al. (2000). This represents a situation in which side trades can take place outside the book, as is the case if market makers can also place fill-or-kill orders or make side trades on dark pools. ${ }^{1}$ In the convex-tariff game, market makers can only post convex tariffs, as in Back and Baruch (2013). This represents a situation in which all trades must take place through the book, as is the case if market makers are restricted to placing collections of limit orders.

Our main finding is that in both games, adverse selection severely restricts equilibrium outcomes. First, pure-strategy equilibria with convex tariffs in fact feature linear pricing, in contrast to the equilibria with strictly convex tariffs obtained in continuous-type models. Second, such linear-pricing equilibria essentially exist only in the knife-edge private-value case where there is no adverse selection and market makers' marginal cost is constant. In all other cases, pure-strategy equilibria typically fail to exist when there are sufficiently many types. Indeed, any candidate equilibrium is such that all types who trade do so at the same marginal cost for the market makers, a property that is increasingly difficult to satisfy when the number of types grows large. These results hold irrespective of the distribution of types as long as it remains discrete, both in the arbitrary-tariff game and, in the absence of wealth effects, in the convex-tariff game. In addition, in the arbitrary-tariff game, they extend to the case where the market makers have strictly convex order-handling costs, even under private values.

The proof of these results proceeds by necessary conditions. That is, we assume that a pure-strategy equilibrium with convex tariffs exists and we investigate its properties. The logical structure of our argument can be broken down into four steps.

Indirect utilities We first notice that, fixing the convex tariffs posted in equilibrium by all but one market maker, the preferences of the insider over the trades she can make with this market maker exhibit a fair amount of regularity. In particular, the corresponding indirect utility functions for the different insider's types satisfy weak quasiconcavity and weak single-crossing properties. This allows us to use standard mechanismdesign techniques (in the arbitrary-tariff game) or standard price-theory arguments (in the convex-tariff game) to analyze the equilibrium best response of each market maker.

Linear pricing Although the weak single-crossing property does not guarantee that the quantity purchased by the insider from any given market maker is nondecreasing in her type, it does ensure that she always has a best response that satisfies this property. We show that this implies that each market maker can break ties in his favor as long as he sticks to nondecreasing quantities. Such ties, expressed in terms of the insider's indirect utility functions, play a key role in our discrete-type model; this reflects that no

\footnotetext{
${ }^{1}$ A fill-or-kill order must be entirely executed or else it is cancelled; thus, unlike for limit orders, partial execution is not feasible. A dark pool is a trading platform in which trades take place over the counter.
} 
market maker can be indispensable for providing the insider with her aggregate equilibrium trades. Under competition, a remarkable consequence of this tie-breaking result is that any pure-strategy equilibrium with convex tariffs and nondecreasing individual quantities must feature linear pricing. In the arbitrary-tariff game, this linear-pricing result requires surprisingly little structure on the market makers' profit functions. Still, a key ingredient is that the set of types is discrete, because this discreteness allows for a precise targeting of individual types and drives the impossibility of a market maker being indispensable. Another important geometric observation is that binding incentive constraints cannot be reconciled with convex pricing when the insider's preferences are strictly convex; in particular, a monopoly would never want to post a convex tariff. Convex pricing may occur only when competing market makers post linear tariffs, thereby making indirect utility functions locally linear.

Market breakdown The second step of the argument focuses on equilibria with linear tariffs and nondecreasing individual quantities. We show that, except in the abovementioned pure private-value case, such equilibria exhibit an extreme form of market breakdown. For instance, in the pure common-value case where the market makers' marginal cost is strictly increasing in the insider's type, only the highest type can trade in equilibrium, reflecting that each market maker has an incentive to reduce his supply at the equilibrium price by placing an appropriate limit order. Equilibria with linear tariffs and nondecreasing individual quantities then only exist under exceptional circumstances. Indeed, all types except the highest one must not be willing to trade at the equilibrium price; however, this is unlikely to be the case when some types have preferences close to the highest one's, as when we let the number of types grow large so as to approximate an interval. This proves our main results for the special case of pure-strategy equilibria with nondecreasing individual quantities.

Other equilibrium outcomes The argument so far focuses on a subset of equilibria, hence leaving open the possibility that equilibria that do not feature nondecreasing individual quantities may exhibit very different properties. To complete the argument, we show that the restriction to nondecreasing individual quantities is actually innocuous. Specifically, we prove that for a large class of profit functions, any pure-strategy equilibrium with convex tariffs can be turned into another equilibrium with the same tariffs and the same expected profits for the market makers, but now with nondecreasing individual quantities. Key to this result is that, for a given profile of convex tariffs, allocations with nondecreasing individual quantities achieve efficient risk sharing among market makers.

The upshot of our analysis, therefore, is that the structure of pure-strategy equilibria in arbitrary discrete-type models is qualitatively different from that arising in the continuous-type models of Biais et al. (2000) and Back and Baruch (2013). When such equilibria exist, market breakdown emerges as a robust prediction of competitive nonlinear pricing in limit-order markets. We complement the above analysis by providing necessary and sufficient conditions for the existence of pure-strategy equilibria. These conditions are eventually violated in the pure common-value case when we approximate a continuous set of types by an increasing sequence of discrete sets of types. As a 
result, the equilibrium correspondence fails to be lower hemicontinuous when we move from discrete-type models to continuous-type models. This confirms and extends in a radical way the results obtained by Attar et al. (2014) in the two-type case.

To overcome this tension between discrete- and continuous-type models, we relax the equilibrium concept by exploring $\varepsilon$-equilibria of the arbitrary-tariff game in two limiting cases of our analysis.

We first examine what happens when the number $K$ of market makers grows large, holding the number of types fixed. We prove that there exists an $\varepsilon$-equilibrium of the arbitrary-tariff game, with $\varepsilon$ on the order of $1 / K^{2}$, that implements the allocation put forward by Glosten (1994). This allocation is competitive in the sense that each marginal quantity is priced at the expected cost of serving the types who purchase it; moreover, it can be implemented by an entry-proof tariff. The intuition for the result is that if $K-1$ market makers each contribute to providing a fraction $1 / K$ of this tariff, then the resulting aggregate tariff is almost entry-proof from the perspective of the remaining market maker.

We then explore the dual scenario in which the number $I$ of types grows large, holding the number of market makers fixed. We prove that there exists an $\varepsilon$-equilibrium of the arbitrary-tariff game, with $\varepsilon$ on the order of $1 / I$, that implements the Biais et al. (2000) allocation. The intuition for the result is that if $K-1$ market makers each post the strictly convex tariff that arises in the symmetric equilibrium characterized by Biais et al. (2000), the same tariff is an approximate best response for the remaining market maker in the discrete-type model when $I$ is large enough. Mathematically, this is because each market maker's equilibrium expected profit in the continuous-type model can be, up to terms of order $1 / I$, approximated in the Riemann sense by the corresponding expected profit in the discrete-type model. Thus, although no sequence of exact equilibria of discrete-type models converges to the Biais et al. (2000) equilibrium, lower hemicontinuity is restored when we broaden the scope of the analysis to $\varepsilon$-equilibria.

\section{Related literature}

It is by now standard to represent trade in a limit-order market as implemented by an auction mechanism in which traders submit orders, to be matched by trading platforms. A uniform limit-order book, where all orders are executed at the market clearing price, can thus be modeled as a uniform-price auction in which traders simultaneously post supply functions. Characterizations of the corresponding supply-function equilibria are provided by Grossman (1981), Klemperer and Meyer (1989), Kyle (1989), and Vives (2011). We instead focus on discriminatory auctions, in which all the limit orders reaching the book must be executed at their prespecified prices. Our setting also differs from models of Treasury-bill auctions, in which it is typically assumed that bidders hold private information, as in Wilson (1979) or Back and Zender (1993).

Many theoretical analyses of limit-order markets focus on the evolution of the book as new traders arrive on the market; we refer to Parlour and Seppi (2008) for a useful survey. In comparison, fewer attempts have been made at understanding the competitive forces leading to aggregate market outcomes. In an important article, Glosten (1994) 
proposes a candidate nonlinear tariff, meant to describe the limit-order book as a whole and that specifies that any additional share beyond any given volume can be bought at a price equal to the expected value of the asset conditional on demand being at least equal to this volume. This tariff is convex, as demand typically increases when the insider has more favorable information, and it yields zero expected profit to the market makers. Moreover, this is the only convex tariff that is robust to entry, in the sense that no uninformed market maker can gain by proposing additional trades to the insider on top of those the tariff makes available.

As acknowledged in Glosten (1998), however, a natural question is whether this tariff can be sustained in an equilibrium of a trading game with strategic market makers. This approach has been pursued by Biais et al. (2000, 2013), Back and Baruch (2013), and Attar et al. (2014). From a methodological viewpoint, these articles contribute to the theory of nonexclusive competition under adverse selection, an issue first explored by Pauly (1974), Jaynes (1978), and Hellwig (1988) in the context of insurance markets. We make a further step in this direction by providing a general strategic analysis of the discrete-type model and by exploring its implications in the limit when the number of market makers or the number of possible types grows large.

Our results allow us to draw a sharp comparison with standard exclusive-competition models of adverse selection, such as Rothschild and Stiglitz's (1976). First, the lack of lower hemicontinuity of the pure-strategy-equilibrium correspondence we highlight is intrinsically tied to the nonexclusive nature of competition. Indeed, lower hemicontinuity is vacuously satisfied under exclusive competition: as in our model, necessary conditions for the existence of pure-strategy equilibria become increasingly restrictive when we increase the number of types and, in the continuous-type limit, no purestrategy equilibrium exists, as shown by Riley $(1985,2001)$. Second, we exploit the property that the Glosten (1994) allocation can be implemented by an entry-proof tariff to construct $\varepsilon$-equilibria when there are many market makers. This result has no counterpart under exclusive competition, because a pure-strategy equilibrium then fails to exist precisely when the Rothschild and Stiglitz (1976) allocation is not entry-proof, independently of the number of competing firms.

The paper is organized as follows. Section 2 describes the model. Section 3 states our main results. Section 4 establishes that pure-strategy equilibria with convex tariffs and nondecreasing individual quantities feature linear pricing. Section 5 shows that such equilibria exist only in exceptional cases when there is adverse selection or when market makers have strictly convex costs. Section 6 extends these results to all equilibria with convex tariffs, completing the proof of our main results. Section 7 offers necessary and sufficient conditions for the existence of a pure-strategy equilibrium. Section 8 discusses how to interpret our results and relate them to the literature. Section 9 considers $\varepsilon$-equilibria in the competitive and continuous limits of the model. Section 10 concludes. Proofs not given in the text can be found in the Appendix and, for technical lemmas, in the Supplemental Material, available in supplementary file on the journal website, http://econtheory.org/supp/2708/supplement.pdf. 


\section{THE MODEL}

Our model features a privately informed insider who can trade an asset with several market makers. Unless otherwise stated, we allow for general payoff functions and arbitrary discrete distributions for the insider's type.

\subsection{The insider}

Because shares are homogeneous, the insider cares only about the aggregate quantity $Q$ she purchases from the market makers and the aggregate transfer $T$ she makes in return. Following Back and Baruch (2013) and Biais et al. (2013), we focus on the ask side of the market and thus require that $Q$ be nonnegative. The insider (she) is privately informed of her preferences. Her type $i$ can take a finite number $I \geq 1$ of values with strictly positive probabilities $m_{i}$. Type $i$ 's preferences over aggregate trades $(Q, T)$ are represented by a utility function $U_{i}(Q, T)$ that is continuous and strictly quasiconcave in $(Q, T)$ and strictly decreasing in $T$. The following strict single-crossing property (Milgrom and Shannon 1994) is the key determinant of the insider's behavior.

Assumption SC- $U$. For all $i<j, Q<Q^{\prime}, T$, and $T^{\prime}$,

$$
U_{i}(Q, T) \leq U_{i}\left(Q^{\prime}, T^{\prime}\right) \quad \text { implies } \quad U_{j}(Q, T)<U_{j}\left(Q^{\prime}, T^{\prime}\right) .
$$

In words, a higher type is more willing to increase her purchases than are lower types. As an illustration, consider the demand of type $i$ at price $p$ :

$$
D_{i}(p) \equiv \arg \max \left\{U_{i}(Q, p Q): Q \in \mathbb{R}_{+} \cup\{\infty\}\right\} .
$$

The continuity and strict quasiconcavity of $U_{i}$ ensure that $D_{i}(p)$ is uniquely defined and continuous in $p$. Moreover, Assumption SC- $U$ implies that, for each $p, D_{i}(p)$ is nondecreasing in $i$. To avoid discussing knife-edge cases involving kinks, we strengthen this property by requiring that demand be strictly increasing in the insider's type, in the following sense.

Assumption ID- $U$. For all $i<j$ and $p$,

$$
0<D_{i}(p)<\infty \text { implies } D_{i}(p)<D_{j}(p) .
$$

A sufficient condition for Assumptions SC- $U$ and ID- $U$ to hold is that the marginal rate of substitution $\tau_{i}(Q, T)$ of shares for transfers be well defined and strictly increasing in $i$ for all $(Q, T)$. Assumptions SC- $U$ and ID- $U$ are maintained throughout the paper.

Some of our results are valid for such general utility functions, allowing for wealth effects (Theorem 1). Others rely on quasilinearity (Theorem 2), though not on any particular parametrization of the insider's utility function. The corresponding assumption is as follows.

Assumption QL- $U$. The insider has quasilinear utility $U_{i}(Q, T) \equiv u_{i}(Q)-T$, where $u_{i}(Q)$ is differentiable and strictly concave in $Q$. 
Under this additional assumption, Assumptions SC- $U$ and ID- $U$ require only that the derivative $u_{i}^{\prime}(Q)$ be strictly increasing in $i$ for all $Q$. For instance, in Biais et al. (2000), $U_{i}(Q, T) \equiv \theta_{i} Q-\left(\alpha \sigma^{2} / 2\right) Q^{2}-T$, reflecting that the insider has constant absolute risk aversion (CARA) utility with absolute risk aversion $\alpha$ and faces residual Gaussian risk with variance $\sigma^{2}$. Assumptions SC- $U$ and ID- $U$ then hold if $\theta_{i}$ is strictly increasing in $i$. In this case, the insider's demand is independent of her wealth, as in Glosten (1994) and Back and Baruch (2013).

\subsection{The market makers}

There are $K \geq 2$ market makers. Each market maker (he) only cares about the quantity $q$ that he provides to the insider and the transfer $t$ he receives in return. Again, we focus on the ask side of the market and thus require that $q$ be nonnegative. Market maker $k$ 's preferences over trades $(q, t)$ with type $i$ are represented by a profit function $v_{i}^{k}(q, t)$ that is continuous and weakly quasiconcave in $(q, t)$ and strictly increasing in $t$. In the common-value case, the profit from a trade depends on the insider's type, as in Glosten and Milgrom (1985), Kyle (1985), Glosten (1994), or Biais et al. (2000). This contrasts with the private-value case, in which the profit from a trade is independent of the insider's type. We allow for both cases by requiring that each market maker weakly prefer to increase his sales to lower types than to higher types.

Assumption SC- $v$. For all $k, i<j, q<q^{\prime}, t$, and $t^{\prime}$,

$$
v_{i}^{k}(q, t) \geq v_{i}^{k}\left(q^{\prime}, t^{\prime}\right) \quad \text { implies } \quad v_{j}^{k}(q, t) \geq v_{j}^{k}\left(q^{\prime}, t^{\prime}\right) .
$$

Assumption SC- $v$ is maintained throughout the paper. Assumptions SC- $U$ and SC$v$ imply that an insider with a higher type is willing to purchase more shares but faces market makers who are weakly more reluctant to serve him. Our model thus typically features adverse selection, with private values as a limiting case.

Some of our results are valid for such general profit functions, allowing for risk aversion and inventory costs, as in Stoll (1978) and Ho and Stoll $(1981,1983)$. Others require more structure, notably in the form of quasilinearity and symmetry assumptions (Theorems 1 and 2). First, we may follow Glosten (1994), Biais et al. (2000), and Back and Baruch (2013) and assume that market makers have identical linear profit functions. The corresponding assumption is as follows.

Assumption L- $v$. For each $i$, each market maker $k$ earns a profit $v_{i}^{k}(q, t) \equiv t-c_{i} q$ when he trades $(q, t)$ with type $i$, where $c_{i}$ is the strictly positive cost of serving type $i$.

Here, the market makers are assumed to be risk-neutral and $c_{i}$ may be thought of as the expected liquidation value of the asset when the insider is of type $i$. Assumption SC$v$ then amounts to imposing that $c_{j} \geq c_{i}$ when $j>i$, reflecting that market makers are less willing to sell the asset when they know that its liquidation value is likely to be high. Alternatively, we may follow Roll (1984) and assume that each market maker incurs a strictly increasing and strictly convex order-handling cost when selling shares. The corresponding assumption is as follows. 
Assumption C- $v$. For each $i$, each market maker $k$ earns a profit $v_{i}^{k}(q, t) \equiv t-c_{i}(q)$ when he trades $(q, t)$ with type $i$, where the cost $c_{i}(q)$ is strictly convex in $q$, with $c_{i}(0) \equiv 0$.

Assumption SC- $v$ then amounts to imposing that $\partial^{-} c_{j}\left(q^{\prime}\right) \geq \partial^{+} c_{i}(q)$ when $j>i$ and $q^{\prime}>q .^{2}$ Assumption C- $v$ generalizes Roll (1984) by allowing for both order-handling and adverse-selection costs.

We state our main results for the case where the market makers' profit functions satisfy Assumption L- $v$ or Assumption C- $v$ (Theorems 1 and 2). We, however, indicate in the course of the formal analysis the extent to which some of our results can be extended to more general and possibly heterogenous profit functions.

\subsection{Timing and strategies}

The game unfolds as follows:

Stage 1. The market makers $k=1, \ldots, K$ simultaneously post tariffs $t^{k}$. Each tariff $t^{k}$ is defined over a domain $A^{k} \subset \mathbb{R}_{+}$that contains 0 , with $t^{k}(0) \equiv 0$.

Stage 2. After privately learning her type, the insider purchases a quantity $q^{k} \in A^{k}$ from each market maker $k$, for which she pays in total $\sum_{k} t^{k}\left(q^{k}\right)$.

A pure strategy $s$ for the insider maps any tariff profile $\left(t^{1}, \ldots, t^{K}\right)$ and any type $i$ into a quantity profile $\left(q^{1}, \ldots, q^{K}\right)$. To ensure that type $i$ 's problem,

$$
\max \left\{U_{i}\left(\sum_{k} q^{k}, \sum_{k} t^{k}\left(q^{k}\right)\right):\left(q^{1}, \ldots, q^{K}\right) \in A^{1} \times \cdots \times A^{K}\right\},
$$

always has a solution, we require that the domains $A^{k}$ be compact and that each tariff $t^{k}$ be lower semicontinuous over $A^{k}$. This, in particular, allows market makers to offer finite menus of trades, including the null trade $(0,0)$. In any case, these requirements involve no loss of generality on the equilibrium path, as any equilibrium can be sustained by tariffs that satisfy them. Off the equilibrium path, they only ensure that the insider has an optimal quantity profile following any unilateral deviation by a market maker.

We call the above game the arbitrary-tariff game. In this game, market makers can post arbitrary tariffs, as in Biais et al. (2000) and Attar et al. (2011, 2014). It is also interesting to study the convex-tariff game, in which market makers can only post convex tariffs, as in Back and Baruch (2013). It is then required of any admissible tariff $t^{k}$ for market maker $k$ that the domain $A^{k}$ be a compact interval containing 0 and that $t^{k}$ be convex over $A^{k}$. The set of convex tariffs is the closure of the set of tariffs resulting from finite collections of limit orders; that is, any convex tariff can be interpreted as a (possibly infinite) collection of (possibly infinitesimal) limit orders.

\footnotetext{
${ }^{2}$ For any convex function $g$ defined over a convex subset of $\mathbb{R}$, we use the notation $\partial g(x), \partial^{-} g(x)$, and $\partial^{+} g(x)$ to denote the subdifferential of $g$ at $x$, the minimum element of $\partial g(x)$, and the maximum element of $\partial g(x)$, respectively. Hence $\partial g(x)=\left[\partial^{-} g(x), \partial^{+} g(x)\right]$ (Rockafellar 1970, Section 23).
} 


\subsection{Equilibria with convex tariffs}

We focus until Section 9 on pure-strategy perfect-Bayesian equilibria $\left(t^{1}, \ldots, t^{K}, s\right)$ with convex tariffs $t^{k}$. This last restriction is hardwired in the market makers' strategy spaces in the convex-tariff game, whereas it is a requirement on equilibrium strategies in the arbitrary-tariff game. The focus on convex tariffs intends to describe an idealized discriminatory limit-order book in which market makers place limit orders or collections of limit orders. Such instruments are known to have nice efficiency properties under complete information. ${ }^{3}$ It is thus natural to ask how well they perform under adverse selection. Characterizing equilibria with convex tariffs of the arbitrary-tariff game amounts to studying the robustness of the book to side trades that may take place outside the book (Theorem 1); by contrast, characterizing equilibria of the convex-tariff game amounts to studying the inherent stability of the book (Theorem 2). We perform the latter exercise under stronger assumptions than the former, so that the two sets of results are not nested.

Focusing on equilibria with convex tariffs also ensures that, on the equilibrium path, the insider's preferences over profiles of individual trades are well behaved, as we now show. Let us first recall that the convexity of the tariffs is preserved under aggregation. In particular, the minimum aggregate transfer the insider must make in return for an aggregate quantity $Q$, namely,

$$
T(Q) \equiv \min \left\{\sum_{k} t^{k}\left(q^{k}\right): q^{k} \in A^{k} \text { for all } k \text { and } \sum_{k} q^{k}=Q\right\},
$$

is convex in $Q$ in equilibrium. ${ }^{4}$ As a consequence and because the utility functions $U_{i}$ are strictly quasiconcave, each type $i$ has a uniquely determined aggregate equilibrium demand $Q_{i}$, which is nondecreasing in $i$ under Assumption SC- $U$. Similarly, if the insider wants to purchase an aggregate quantity $Q^{-k} \in \sum_{l \neq k} A^{l}$ from the market makers other than $k$, the minimum transfer she must make in return,

$$
T^{-k}\left(Q^{-k}\right) \equiv \min \left\{\sum_{l \neq k} t^{l}\left(q^{l}\right): q^{l} \in A^{l} \text { for all } l \neq k \text { and } \sum_{l \neq k} q^{l}=Q^{-k}\right\}
$$

is convex in $Q^{-k}$ in equilibrium. In turn, each type $i$ evaluates any trade $(q, t)$ she may make with market maker $k$ through the indirect utility function

$$
z_{i}^{-k}(q, t) \equiv \max \left\{U_{i}\left(q+Q^{-k}, t+T^{-k}\left(Q^{-k}\right)\right): Q^{-k} \in \sum_{l \neq k} A^{l}\right\} .
$$

Observe that the maximum in (3) is attained and that $z_{i}^{-k}(q, t)$ is strictly decreasing in $t$ and continuous in $(q, t) .{ }^{5}$ The following lemma is key to our results.

\footnotetext{
${ }^{3}$ Biais et al. (1998) show in the single-type case that equilibria of the convex-tariff game exist and are efficient; see also Dubey (1982). A difference with our setting, though, is that these authors assume that the insider's demand for shares is perfectly inelastic.

${ }^{4}$ Formally, $T$ is the infimal convolution of the individual tariffs $t^{k}$ posted by the market makers (Rockafellar 1970, Theorem 5.4). Notice that $\sum_{k} A^{k}=\left[0, \sum_{k} \max A^{k}\right]$ when the tariffs $t^{k}$ are convex.

${ }^{5}$ This follows from Berge's maximum theorem (Aliprantis and Border 2006, Theorem 17.31).
} 
Lemma 1. For any profile $\left(t^{1}, \ldots, t^{K}\right)$ of convex tariffs, and for all $k$ and $i, z_{i}^{-k}(q, t)$ is weakly quasiconcave in $(q, t)$. Moreover, for each $k$, the family of functions $z_{i}^{-k}$ satisfies the following weak single-crossing property.

Property SC- $z$. For all $k, i<j, q \leq q^{\prime}, t$, and $t^{\prime}$,

$$
\begin{array}{ll}
z_{i}^{-k}(q, t) \leq z_{i}^{-k}\left(q^{\prime}, t^{\prime}\right) & \text { implies } \quad z_{j}^{-k}(q, t) \leq z_{j}^{-k}\left(q^{\prime}, t^{\prime}\right) \\
z_{i}^{-k}(q, t)<z_{i}^{-k}\left(q^{\prime}, t^{\prime}\right) & \text { implies } \quad z_{j}^{-k}(q, t)<z_{j}^{-k}\left(q^{\prime}, t^{\prime}\right) .
\end{array}
$$

Our focus on equilibria with convex tariffs thus ensures that the indirect utility functions $z_{i}^{-k}$ satisfy regularity properties that they inherit from the primitive utility functions $U_{i}{ }^{6}$ It should be noted that, unlike the functions $U_{i}$, the functions $z_{i}^{-k}$ satisfy quasiconcavity and single crossing only in a weak sense. For instance, if all market makers offer to sell any quantity up to some limit at the same price $p$, then several types may be indifferent between two trades with any given market maker. Our analysis pays particular attention to the way in which such ties are broken in equilibrium.

\subsection{On the assumptions of the model}

Before proceeding with the formal analysis, it is worthwhile to discuss some of the key assumptions of the model.

Common values As in Glosten (1989) and Biais et al. (2000), the insider in our model may trade for speculative reasons, so as to use her information on the value of the asset, and for hedging reasons, as when she has an endowment in this asset and faces residual risk about its value. Her willingness to trade thus incorporates both commonand private-value components. In this interpretation, informational signals and hedging needs are the insider's private information. The market makers' cost of serving the insider is the expectation of the value of the asset, conditional on the insider's willingness to trade; it is natural to assume that this cost is higher, the more the insider is willing to trade.

Convex pricing Our focus on equilibria with convex pricing is institutionally motivated by the discriminatory limit-order book. Yet other markets present this characteristic. For instance, in the credit-card market, issuers offer credit cards with various threshold limits and interest rates. Analogous to limit orders, we can think of the former as maximum quantities and of the latter as limit prices. Consumers effectively face convex tariffs, as they first and foremost subscribe to the credit cards with the lowest interest rates. Finally, consumers have different probabilities of repayment and anticipated liquidity needs. Their willingness to trade thus incorporates both common- and private-value components.

\footnotetext{
${ }^{6}$ This contrasts with the analysis in Attar et al. (2011), where the presence of a capacity constraint and the absence of restrictions on equilibrium menus could result in indirect utility functions that need not be continuous or satisfy single crossing.
} 
Nonanonymity Our analysis focuses on the case where there is a single insider who is thus perfectly identifiable by the market makers. When there are several insiders whose identity is not observed by the market makers, each of them can make as many purchases as she wants along any given tariff. As a result, market makers lose the ability to restrict the quantities they sell at the lowest limit price, at odds with the discriminatory limit-order book, and convex tariffs effectively become linear. In that case, as in Pauly (1974), a linear-price equilibrium can always be sustained, in which market makers post a price $p$ satisfying

$$
p=\frac{\mathbf{E}\left[c_{i} D_{i}(p)\right]}{\mathbf{E}\left[D_{i}(p)\right]},
$$

and thus equal to the expected cost of serving the types who choose to trade at price $p$, with weights given by their respective demands $D_{i}(p)$.

Bilateral contracting Our results extend to the multiple-insider case under the following assumptions. First, each market maker is able to observe each insider's identity. Second, contracting remains bilateral: market makers cannot observe the tariffs posted by their competitors or the trades they make with each insider. Third, the aggregate profit of a market maker is equal to the sum of the profits he earns with all insiders, which requires linear costs. Then, as shown by Han (2006), each interaction between an insider and the market makers can be studied in isolation. In practice, the book evolves over time as orders are executed; this requires a dynamic modeling, which is outside the scope of this paper.

\section{The MAin Results}

Our central theorems provide necessary conditions for equilibria with convex tariffs.

THEOREM 1. Suppose that the arbitrary-tariff game has a pure-strategy equilibrium with convex tariffs. Then, in any such equilibrium, the following statements hold:

(i) If market makers have linear costs (Assumption L-v), then all trades take place at a constant price equal to the highest cost $c_{I}$. Each type i purchases $D_{i}\left(c_{I}\right)$ in the aggregate and all the types who trade have the same cost $c_{i}=c_{I}$.

(ii) If market makers have strictly convex costs (Assumption $C-v$ ), then all trades take place at a constant price $p$. Only type I may trade. If $D_{I}(p)>0$, then $p \in$ $\partial c_{I}\left(D_{I}(p) / K\right)$ and all market makers sell the same quantity $D_{I}(p) / K$ to type $I$.

THEOREM 2. Suppose that the insider has quasilinear utility (Assumption $Q L-U$ ), that market makers have linear costs (Assumption L-v), and that the convex-tariff game has a pure-strategy equilibrium. Then, in any such equilibrium, all trades take place at a constant price equal to the highest cost $c_{I}$. Each type $i$ purchases $D_{i}\left(c_{I}\right)$ in the aggregate and all the types who trade have the same cost $c_{i}=c_{I}$. 
We prove these two theorems in Sections 4-6. To do so, we presuppose the existence of an equilibrium $\left(t^{1}, \ldots, t^{K}, s\right)$ with convex tariffs of either game and we investigate its properties. In the arbitrary-tariff game, this equilibrium should be robust to deviations by market makers to arbitrary tariffs, whereas in the convex-tariff game, it should only be robust to deviations by market makers to convex tariffs. We provide necessary and sufficient conditions for the existence of equilibria in Section 7.

\section{LINEAR PRICING}

In this section, as well as in the next one, we focus on equilibria with nondecreasing individual quantities, in which the quantity $q_{i}^{k}$ purchased by the insider from each market maker $k$ is nondecreasing in her type $i$. This prima facie restriction is motivated by the fact that, under Assumption SC- $U$, aggregate quantities purchased in equilibrium are nondecreasing in the insider's type. We show that any equilibrium with convex tariffs that satisfies this property features linear pricing. Section 6 extends this linear-pricing result to all equilibria with convex tariffs, showing that the restriction to nondecreasing individual quantities involves no loss of generality.

\subsection{The arbitrary-tariff game}

We first consider the arbitrary-tariff game, in line with Biais et al. (2000). We start with a tie-breaking lemma that provides a lower bound for each market maker's equilibrium expected profit given the tariffs posted by his competitors. We then use this lemma to prove our linear-pricing result.

4.1.1 How the market makers can break ties Consider an equilibrium $\left(t^{1}, \ldots, t^{K}, s\right)$ with convex tariffs of the arbitrary-tariff game and suppose that market maker $k$ deviates to a menu $\left\{\left(q_{i}, t_{i}\right): i=1, \ldots, I\right\} \cup\{(0,0)\}$ designed so that type $i$ selects the trade $\left(q_{i}, t_{i}\right)$. For this to be the case, the following incentive-compatibility and individual-rationality constraints must be satisfied:

$$
z_{i}^{-k}\left(q_{i}, t_{i}\right) \geq z_{i}^{-k}\left(q_{j}, t_{j}\right) \quad \text { and } \quad z_{i}^{-k}\left(q_{i}, t_{i}\right) \geq z_{i}^{-k}(0,0), \quad i, j=1, \ldots, I .
$$

Notice that these constraints are formulated in terms of the insider's indirect utility functions, which are endogenous objects. Property SC- $z$ suggest that we consider a subset of these constraints, namely, the downward local constraints

$$
z_{i}^{-k}\left(q_{i}, t_{i}\right) \geq z_{i}^{-k}\left(q_{i-1}, t_{i-1}\right), \quad i=1, \ldots, I,
$$

with $\left(q_{0}, t_{0}\right) \equiv(0,0)$ by convention to handle the individual-rationality constraint of type 1. Clearly, these constraints are not sufficient to ensure that each type $i$ will choose to trade $\left(q_{i}, t_{i}\right)$ following market maker $k$ 's deviation. First, local upward incentive constraints need not be satisfied. Second, and more importantly, some type may be indifferent between two trades, thus creating some ties. Nevertheless, as we shall now see, 
as long as he sticks to menus with nondecreasing quantities, market maker $k$ can secure the expected profit he would obtain if he could break such ties in his favor. Define

$$
V^{k}\left(t^{-k}\right) \equiv \sup \left\{\sum_{i} m_{i} v_{i}^{k}\left(q_{i}, t_{i}\right)\right\},
$$

where the supremum in (8) is taken over all menus $\left\{\left(q_{i}, t_{i}\right): i=0, \ldots, I\right\}$ that satisfy (7) and that have nondecreasing quantities, that is, $q_{i} \geq q_{i-1}$ for all $i$.

LemMA 2. In any pure-strategy equilibrium $\left(t^{1}, \ldots, t^{K}, s\right)$ with convex tariffs of the arbitrary-tariff game, each market maker $k$ 's expected profit is at least $V^{k}\left(t^{-k}\right)$.

The intuition is that, from any menu satisfying the constraints in (8), we can play both with transfers (which we can increase if (7) does not bind for some type) and with quantities (so as to eliminate cycles of binding incentive-compatibility constraints) to build another menu with no lower expected profit such that (6) holds. We can then slightly perturb transfers to make these constraints strict inequalities, which ensures that the insider has a unique best response. This result relies only on Assumptions SC$U$ and SC- $v$. In particular, market makers need not have identical, quasilinear, or even quasiconcave profit functions.

4.1.2 Equilibria with nondecreasing individual quantities The above tie-breaking lemma suggests that we first focus on equilibria with nondecreasing individual quantities, that is, $q_{i}^{k} \geq q_{i-1}^{k}$ for all $i$ and $k$. Suppose, therefore, that such an equilibrium exists. The equilibrium trades of market maker $k$ then satisfy all the constraints in problem (8). An immediate consequence of Lemma 2 is thus that these trades must form a solution to (8). Because the functions $z_{i}^{-k}$ are strictly decreasing in transfers and weakly quasiconcave, it follows that the downward local constraints (7) must bind. This standard result turns out to be very demanding when equilibrium tariffs are convex. Indeed, consider a type who exhausts aggregate supply at some marginal price $p$. When facing a given market maker, this type never wants to mimic another type who does not do likewise because she would end up paying too much for her aggregate demand. In these circumstances, we may wonder how to build a chain of binding downward local constraints that goes all the way down to the null trade.

Let us make these points more formally. When market maker $k$ posts a convex tariff $t^{k}$, his supply correspondence $s^{k}$ is the inverse of the subdifferential of $t^{k}$ (Biais et al. 2000, Definition 2). That is, for any quantity $q$ and marginal price $p$,

$$
q \in s^{k}(p) \text { if and only if } p \in \partial t^{k}(q) \text {. }
$$

The set $s^{k}(p)$ is a nonempty interval with lower and upper bounds $\underline{s}^{k}(p)$ and $\bar{s}^{k}(p)$ that are nondecreasing in $p$. When $\underline{s}^{k}(p)<\bar{s}^{k}(p), t^{k}$ is affine with slope $p$ over $s^{k}(p)$. We let $\underline{S}(p) \equiv \sum_{k} \underline{s}^{k}(p)$ and $\bar{S}(p) \equiv \sum_{k} \bar{s}^{k}(p)$. Observe that $\bar{s}^{k}$ is right-continuous for all $k$ and that $\bar{S}$ inherits this property.

Now suppose, to the contrary, that for some $i$ and $p$, we have, in equilibrium,

$$
Q_{i} \geq \bar{S}(p)>0
$$


For this value of $p$, consider the lowest such $i$; with a slight abuse of notation, denote it again by $i$. Because type $i$ has strictly convex preferences and her aggregate equilibrium demand $Q_{i}$ is uniquely determined, and because, to satisfy this demand, she exhausts aggregate supply $\bar{S}(p)$ at marginal price $p$, any of her best responses must be such that she purchases at least $\bar{s}^{k}(p)$ from each market maker $k$ : otherwise, she would end up paying more than $T\left(Q_{i}\right)$ for $Q_{i}$. As the downward local constraints (7) of type $i$ must bind for all $k$, two cases may arise.

Case 1: $i>1$. Because $i$ is the lowest type such that $Q_{i} \geq \bar{S}(p)$, we must have $Q_{i-1}<$ $\bar{S}(p)$ and thus $q_{i-1}^{k}<\bar{s}^{k}(p)$ for some $k$. Hence the incentive-compatibility constraint (7) of type $i$ cannot bind for market maker $k$, a contradiction.

Case 2: $i=1$. Because $\bar{S}(p)>0$, at least one market maker $k$ must offer $\bar{s}^{k}(p)>0$ at marginal price $p$. Hence the individual-rationality constraint (7) of type 1 cannot bind for market maker $k$, once again a contradiction.

This shows that, for any marginal price $p$ at which aggregate supply is strictly positive, all types must purchase an aggregate quantity below this level: $Q_{i}<\bar{S}(p)$ for all $i$ if $\bar{S}(p)>0$. As $\bar{S}$ is right-continuous, we can safely consider the infimum of the set of such prices; with a slight abuse of notation, denote it again by $p$. At marginal price $p$, either aggregate supply is zero and there is no trade or aggregate supply is strictly positive and, because $p$ is the infimum of the set of marginal prices at which supply is strictly positive, the insider faces an aggregate tariff $T$ that is linear with slope $p$ up to $\bar{S}(p)$. Because, by the above reasoning, $Q_{i}$ is strictly less than $\bar{S}(p)$ for all $i$, each type $i$ must purchase $D_{i}(p)$ in the aggregate. Hence the following result holds.

Proposition 1. In any pure-strategy equilibrium with convex tariffs and nondecreasing individual quantities of the arbitrary-tariff game, there exists a price $p$ such that all trades take place at price $p$ and each type $i$ purchases $D_{i}(p)$ in the aggregate. Moreover, the aggregate tariff $T$ is linear with slope $p$ up to $\bar{S}(p)$, and $D_{i}(p)<\bar{S}(p)$ for all $i$ if $\bar{S}(p)>0$.

The upshot of Proposition 1 is that the possibility of side trades leads to linear pricing. This shows the disciplining role of competition in our model: although market makers can post arbitrary tariffs, they end up trading at the same price. The role of binding downward local constraints is graphically clear, as illustrated in Figure 1: when such a constraint binds for type $i$ and market maker $k$, the latter's equilibrium tariff must be linear over $\left[q_{i-1}^{k}, q_{i}^{k}\right]$ because the indirect utility function $z_{i}^{-k}$ represents convex preferences. In turn, binding local constraints can be reconciled with linear pricing only if these preferences are locally linear. Intuitively, everything happens as if, from the perspective of any market maker, each type who is willing to trade had a valuation for the asset equal to the common price quoted by the other market makers. This, of course, requires competition. Indeed, when there is a monopolistic market maker, it is also optimal for him to make the insider's downward local constraints bind; but, now, these constraints are expressed in terms of the primitive utility functions $U_{i}$. As the latter represent strictly convex preferences, the resulting allocation cannot be implemented by a convex tariff. 


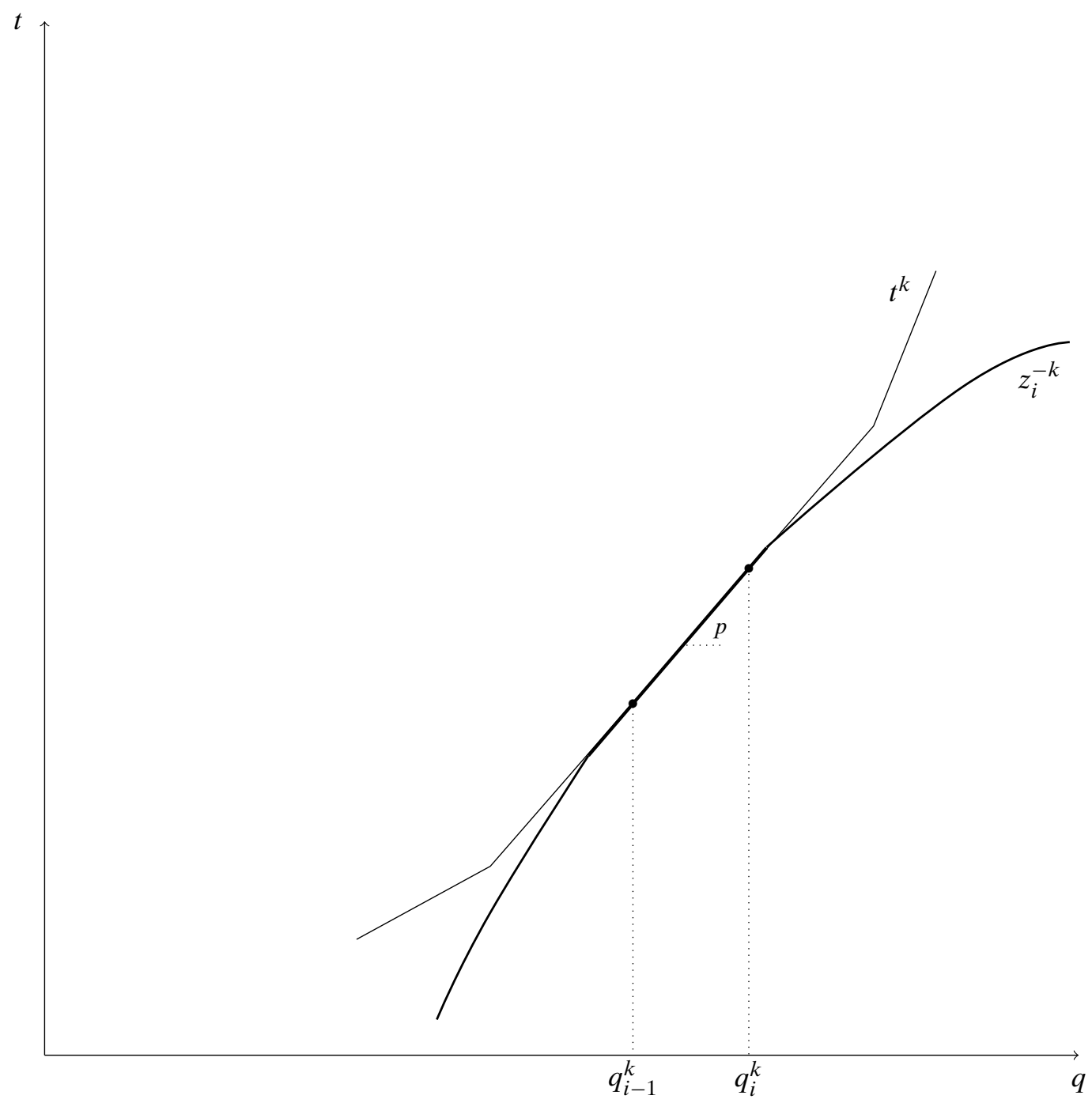

Figure 1. Binding downward local constraints and linearity.

This linear-pricing result is very general: as pointed out in our discussion of Lemma 2, we need not postulate that the market makers have identical, quasilinear, or even quasiconcave profit functions. This result also strikingly differs from those obtained in the continuous-type case by Biais et al. (2000), who show that an equilibrium with strictly convex tariffs and nondecreasing individual quantities exists under certain conditions on players' payoff and distribution functions.

\subsection{The convex-tariff game}

So far, our analysis relies on the market makers' ability to post arbitrary tariffs, including finite menus of trades. A natural question is whether this gives them too much freedom 
to deviate, thus artificially driving the linear-pricing result. To investigate this issue, we now consider the convex-tariff game, in line with Back and Baruch (2013). We conduct the analysis under two additional assumptions. First, we assume that each type has quasilinear utility (Assumption QL- $U$ ). Second, we assume that market makers have linear costs (Assumption L- $v$ ). These assumptions involve some loss of generality, as they exclude wealth effects or insurance considerations. Yet they are general enough to encompass prominent examples studied in the literature, such as the CARA Gaussian example studied by Back and Baruch (2013, Example 1). These assumptions are maintained throughout our analysis of the convex-tariff game.

Focusing on convex tariffs has two main advantages. First, it allows us to rely on simple tools such as supply functions and first-order conditions, the properties of which are well known under convexity assumptions. This contrasts with using arbitrary menus and their cohorts of incentive-compatibility constraints, and makes for more intuitive proofs-some of our arguments are in fact quite direct when considering figures. Second, compared to the arbitrary-tariff game, we reduce the set of deviations available to market makers. This can a priori only enlarge the set of equilibria. In spite of this, for the convex-tariff game, we shall derive a linear-pricing result similar to Proposition 1. The structure of the argument parallels that of Section 4.1: we start with a tie-breaking lemma, which we then use to prove our linear-pricing result.

4.2.1 How the market makers can break ties We first reformulate Lemma 2. Consider an equilibrium $\left(t^{1}, \ldots, t^{K}, s\right)$. Suppose that market maker $k$ deviates to a convex tariff $t$ with domain $A$. For type $i$ to select the quantity $q_{i}$ in this tariff, it must be that

$$
q_{i} \in \arg \max \left\{z_{i}^{-k}(q, t(q)): q \in A\right\} .
$$

This constraint is not sufficient to ensure that type $i$ will choose to purchase $q_{i}$ from market maker $k$ following his deviation. Indeed, type $i$ may be indifferent between two quantities made available by the tariff $t$, thus creating some ties. Nevertheless, as we shall now see, as long as he sticks to nondecreasing quantities, market maker $k$ can secure the expected profit he would obtain if he could break such ties in his favor. Define

$$
V_{\mathrm{co}}^{k}\left(t^{-k}\right) \equiv \sup \left\{\sum_{i} m_{i} v_{i}^{k}\left(q_{i}, t\left(q_{i}\right)\right)\right\},
$$

where the supremum in (11) is taken over all convex tariffs $t$ and all families of quantities $q_{i}$ that satisfy (10) for all $i$ and that are nondecreasing, that is, $q_{i} \geq q_{i-1}$ for all $i$.

Lемма 3. Suppose that the insider has quasilinear utility and market makers have linear costs. Then, in any pure-strategy equilibrium $\left(t^{1}, \ldots, t^{K}, s\right)$ of the convex-tariff game, each market maker $k$ 's expected profit is at least $V_{\mathrm{co}}^{k}\left(t^{-k}\right)$.

When the insider has quasilinear utility, only the marginal-price schedule associated to the tariff $t$ matters to him. As illustrated in Figure 2, we can, therefore, replace the tariff $t$ by a piecewise-linear tariff, labelled $t_{p, q}$, which induces the same best response for the insider and yields market maker $k$ an expected profit no less than that he obtains by 


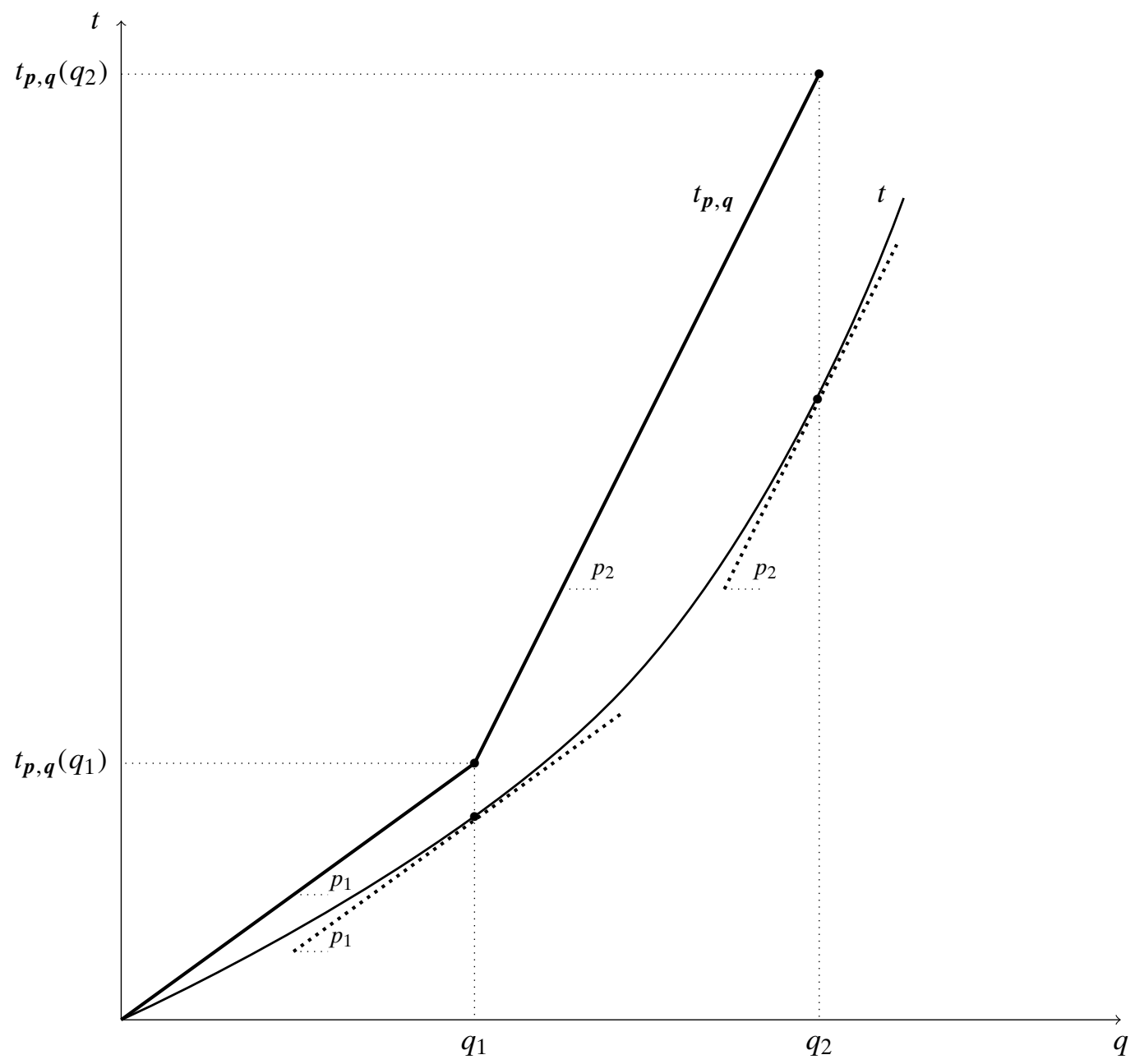

FIGURE 2. Replacing the tariff $t$ by a piecewise-linear tariff $t_{p, q}$ that induces the same choices $q_{i}$ for each insider type $i$ and yields market maker $k$ a strictly higher expected profit.

posting $t$. Furthermore, consider a segment of this piecewise-linear tariff with marginal price $p$ and the set of types who trade on this segment. Under adverse selection, there exists a quantity $\bar{q}$ available along this segment such that market maker $k$ prefers that all types make their purchases closer to this quantity. If $\left(\bar{q}, t_{p, q}(\bar{q})\right)$ is interior to the segment with slope $p$, then this change can be achieved as follows. First, market maker $k$ can increase his expected profit by truncating this segment at $\bar{q}$ : this reduces the quantities purchased by those types, with transfers that are as least as high. In addition, market maker $k$ can slightly lower the marginal price $p$. This ensures that all the relevant types purchase a quantity closer to $\bar{q}$. As illustrated in Figure 3, proceeding in this way for each segment of the tariff $t_{p, q}$, we obtain a second piecewise-linear tariff, labelled $\hat{t}$, which allows market maker $k$ to secure the announced expected profit. 


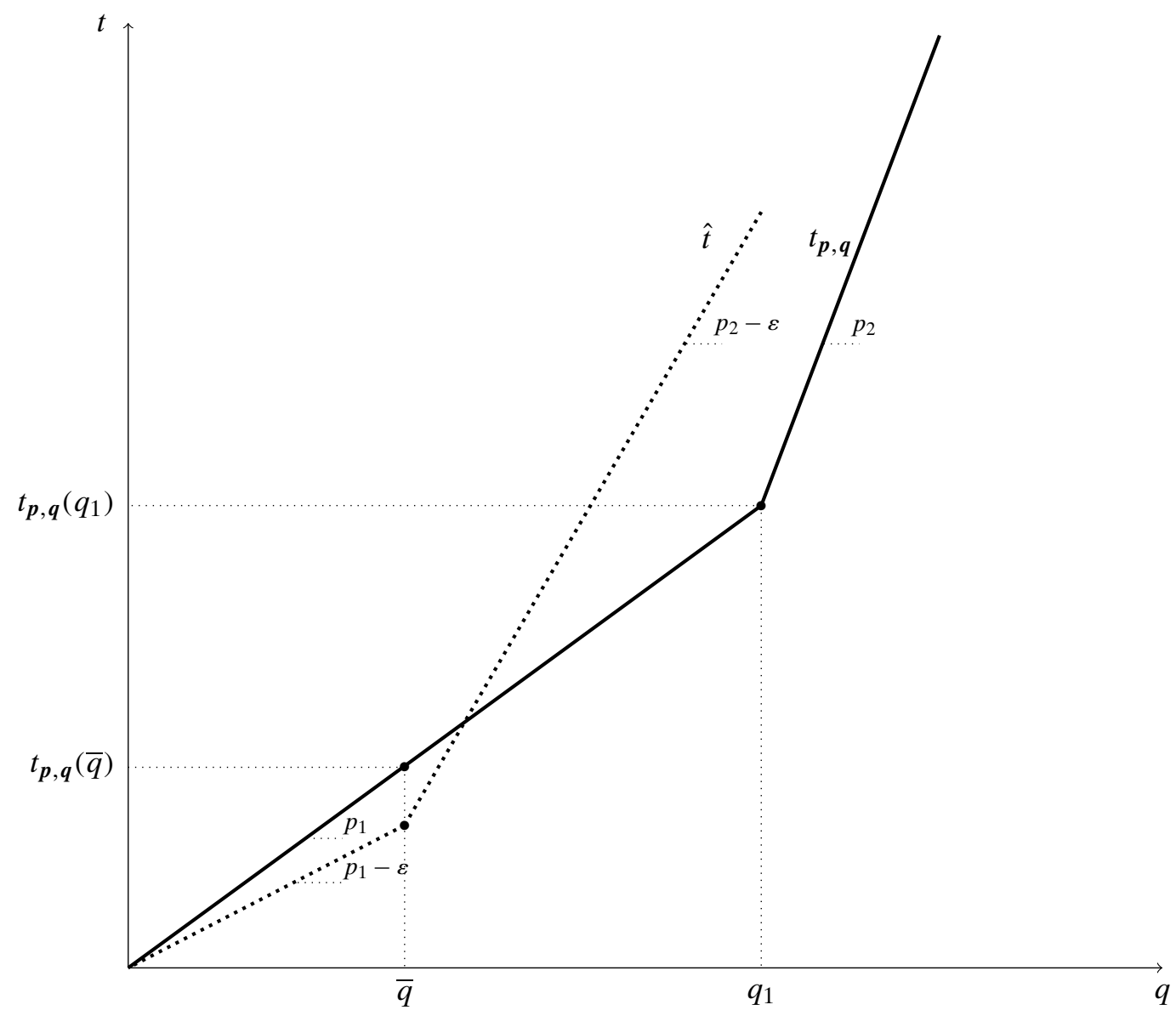

Figure 3. The truncation $\hat{t}$ of the piecewise-linear tariff $t_{p, q}$.

4.2.2 Equilibria with nondecreasing individual quantities Lemma 3 implies that, in any equilibrium with nondecreasing individual quantities, market makers post piecewise-linear tariffs that we can interpret as finite collections of limit orders. Another feature of such an equilibrium that follows from Lemma 3 is that if there is a kink in the aggregate tariff, at least one type exactly trades at this kink; otherwise, at least one market maker could increase his expected profit by slightly raising his marginal price around the corresponding kink in his tariff. Any type trading at a kink exactly exhausts aggregate supply $\bar{S}(p)$ at some marginal price $p$ for which $\bar{S}(p)>0$ and, therefore, has a unique best response that consists of purchasing $\bar{s}^{k}(p)$ from each market maker $k$. As a result, each market maker offering trades at marginal price $p$ is indispensable for any such type to reach her equilibrium utility.

However, simple price-undercutting arguments show that the tariff resulting from the aggregation of all market makers' tariffs shares with the Glosten (1994) competitive tariff described in the Introduction the property that any increase in quantity must be priced at the corresponding expected increase in costs. By construction, this implies 
zero expected profit. But then, if some type were to exhaust aggregate supply $\bar{S}(p)$ at some marginal price $p$ for which $\bar{S}(p)>0$, at least one of the market makers offering trades at this marginal price could raise his tariff in a profitable way. Hence the following result holds.

Pворовітіоn 2. Suppose that the insider has quasilinear utility and market makers have linear costs. Then, in any pure-strategy equilibrium with nondecreasing individual quantities of the convex-tariff game, there exists a price $p$ such that all trades take place at price $p$ and each type i purchases $D_{i}(p)$ in the aggregate. Moreover, the aggregate tariff $T$ is linear with slope $p$ up to $\bar{S}(p)$, and $D_{i}(p)<\bar{S}(p)$ for all if $\bar{S}(p)>0$.

In particular, in the pure common-value case where the cost $c_{i}$ is strictly increasing in the insider's type $i$, the Glosten (1994) allocation cannot be implemented in an equilibrium with nondecreasing individual quantities, except in the degenerate case where only type $I$ happens to trade in that allocation.

\section{MARKET BREAKDOWN}

Our next task consists of determining prices and quantities in the linear-pricing equilibria with nondecreasing individual quantities characterized in Propositions 1 and 2. We show that in both the arbitrary-tariff and the convex-tariff games, such equilibria typically exhibit an extreme form of market breakdown and only exist under exceptional circumstances: in the terminology of Hendren (2014), we either have an instance of equilibrium of market unravelling or, more likely, an instance of unravelling of market equilibrium.

\subsection{Linear costs}

We start with the case where market makers have linear costs (Assumption L- $v$ ), as in Theorems 1(i) and 2. The argument is twofold.

First, a simple price-undercutting argument implies that market makers must make zero expected profit: otherwise, because the functions $D_{i}$ are continuous, any market maker $k$ could claim almost all profits for himself by lowering his price slightly below the equilibrium price $p$. It follows that if trade takes place in equilibrium, $p$ cannot be above the highest possible cost $c_{I}$.

Second, in equilibrium, $p$ cannot be below $c_{I}$ either. Otherwise, each market maker would want to reduce the quantity he sells to type $I$, which he can do by placing a limit order at the equilibrium price, with a well chosen maximum quantity. Formally, in the arbitrary-tariff game, any market maker $k$ could deviate to a menu that would allow types $i<I$ to purchase the equilibrium quantity $q_{i}^{k}$ at price $p$, whereas type $I$ would be asked to purchase only $q_{I-1}^{k}$ at price $p$. Such a menu is incentive-compatible and individually rational, with nondecreasing quantities. Similarly, in the convex-tariff game, any market maker $k$ could deviate to a limit order $t(q)=p \min \left\{q, q_{I-1}^{k}\right\}$. A best response for any type $i<I$ then consists of purchasing $q_{i}^{k}$ as before, whereas a best response for 
type $I$ consists of purchasing $q_{I-1}^{k}$, overall preserving nondecreasing quantities. In either case, it follows from Lemmas 2 and 3 that the variation in market maker $k$ 's expected profit is at most zero; that is,

$$
m_{I}\left(p-c_{I}\right)\left(q_{I-1}^{k}-q_{I}^{k}\right) \leq 0, \quad k=1, \ldots, K
$$

Summing these inequalities over $k$ yields

$$
m_{I}\left(p-c_{I}\right)\left[D_{I-1}(p)-D_{I}(p)\right] \leq 0
$$

which, under Assumption ID- $U$, implies that $p \geq c_{I}$ if $D_{I}(p)>0$. Because aggregate expected profits are zero, we obtain that $p=c_{i}=c_{I}$ for any type $i$ who trades. Hence the following result holds.

Proposition 3. Suppose that market makers have linear costs and, in the convex-tariff game, that the insider has quasilinear utility. Then, in either the arbitrary-tariff or the convex-tariff game, if trade takes place in a linear-pricing equilibrium with nondecreasing individual quantities, then the equilibrium price is equal to the highest cost $c_{I}$ and the cost of serving all the types who trade is equal to $c_{I}$.

This result highlights a tension between zero expected profits in the aggregate and the high equilibrium price $c_{I}$. In the pure private-value case where the cost $c_{i}$ is independent of the insider's type $i$, this tension disappears and we obtain the usual Bertrand result, leading to an efficient outcome. By contrast, in the pure common-value case where the cost $c_{i}$ is strictly increasing in the insider's type $i$, only the highest type $I$ can trade in equilibrium, whereas all types $i<I$ must be excluded from trade. This market breakdown due to adverse selection is much more severe than in the exclusive-competition models of Akerlof (1970) or Rothschild and Stiglitz (1976), as at most one type trades in equilibrium regardless of the distribution of types. Moreover, the conditions for the existence of an equilibrium become very restrictive: we must have $D_{i}\left(c_{I}\right)=0$ for all $i<I$ if an equilibrium is to exist at all. Notice, in particular, that whenever $D_{i}\left(c_{I}\right)>0$ for some $i<I$, there is a sharp discontinuity when we move from the pure private-value case, where $c_{i}=c_{I}$ for all $i$, to the pure common-value case, where $c_{i}<c_{I}$ for all $i<I$ : in the former case, each type efficiently trades at price $c_{I}$ in equilibrium, whereas an equilibrium fails to exist in the latter case even if the cost differences $c_{I}-c_{i}$ are arbitrarily small for all $i<I$.

\subsection{General profit functions}

We now consider more general profit functions for the market makers. This encompasses the case where they are risk-neutral with respect to transfers but have strictly convex order-handling costs, as in Roll (1984), or more general cases allowing for risk aversion, as in Stoll (1978) and Ho and Stoll $(1981,1983)$. We conduct the analysis in the context of the arbitrary-tariff game, as in Theorem 1(ii). Again, the argument is twofold. 
5.2.1 A property of limit orders First, we provide a property of limit orders that does not depend on strategic considerations and may, therefore, be of independent interest. Consider a situation in which all trades must take place at price $p$ and the demands $D_{i}(p)$ are bounded; such is the case, according to Proposition 1 , in any equilibrium with convex tariffs and nondecreasing individual quantities of the arbitrary-tariff game. Market maker $k$ 's most preferred trades at price $p$, assuming that he sticks to nondecreasing quantities, solve

$$
\sup \left\{\sum_{i} m_{i} v_{i}^{k}\left(q_{i}, p q_{i}\right)\right\},
$$

subject to the feasibility constraints

$$
0 \leq q_{i} \leq D_{i}(p), \quad i=1, \ldots, I
$$

and the constraint that quantities be nondecreasing, that is, $q_{i} \geq q_{i-1}$ for all $i$. For any maximum quantity $\bar{q}$, let us define limit-order quantities at price $p$ as

$$
\min \left\{D_{i}(p), \bar{q}\right\}, \quad i=1, \ldots, I .
$$

The following result builds on the quasiconcavity of the functions $v_{i}^{k}$ and on Assumption SC- $v$ to characterize the solutions to problem (12)-(13).

Lemma 4. Let $p$ be such that the demands $D_{i}(p)$ are bounded. Then problem (12)-(13) has a solution with limit-order quantities at price $p$. Besides, if $v_{i}^{k}(q, p q)$ is strictly quasiconcave in $q$ for all $i$, then all the solutions to problem (12)-(13) are limit-order quantities at price $p$.

The proof relies on a very simple reasoning: if the price is high enough to convince a market maker to sell a strictly positive quantity $\bar{q}$ to the highest type $I$, then, according to Assumption SC- $v$, market maker $k$ will want to sell the highest possible quantities-that is, as the case may be, $D_{i}(p)$ or $\bar{q}$-to types $i<I .{ }^{7}$ This result itself is a neat characterization of limit orders: they are the optimal tool under adverse selection for a market maker who must sell nondecreasing quantities at a given fixed price.

5.2.2 Equilibria Our second argument relies on equilibrium considerations. Notice first that in a linear-pricing equilibrium with nondecreasing individual quantities in which all trades take place at price $p$, each market maker $k$ 's expected profit cannot be above the expected profit from his most preferred trades at price $p$. Now, for each $\bar{q}$, market maker $k$ could deviate to the menu $\left\{\left(\min \left\{D_{i}(p), \bar{q}\right\}, p \min \left\{D_{i}(p), \bar{q}\right\}\right): i=\right.$ $1, \ldots, I\} \cup\{(0,0)\}$, offering to sell limit-order quantities at price $p$. Such an offer is incentive-compatible and individually rational, with nondecreasing quantities. It then

\footnotetext{
${ }^{7}$ The proof given in the Supplemental Material allows for a continuum of types. As for the generality of the result, notice that the ordering of the demands $D_{i}(p)$ does not play any particular role. We can relax this assumption, provided that the constraint that quantities be nondecreasing is replaced by the constraint that quantities be co-monotonic with aggregate demand, that is, $D_{i}(p) \leq D_{j}(p)$ implies $q_{i} \leq q_{j}$.
} 
follows from Lemma 2 that, in equilibrium, market maker $k$ can secure the corresponding expected profit, regardless of the value of $\bar{q} .{ }^{8}$ In turn, Lemma 4 implies that, in equilibrium, each market maker $k$ 's expected profit is equal to the value of problem (12)-(13). In particular, the quantities sold by market maker $k$ in equilibrium must be solutions to problem (12)-(13). Finally, if $v_{i}^{k}(q, p q)$ is strictly quasiconcave in $q$ for all $i$ and $k$, such solutions must be limit-order quantities.

Now suppose that market makers have identical profit functions $v_{i}^{k} \equiv v_{i}$ and that, moreover, $v_{i}(q, p q)$ is strictly concave in $q$ for all $i$. Then all problems (12)-(13) are identical and, by strict concavity, they admit a single common solution, which must be a family of limit-order quantities. Each market maker $k$ thus sells in equilibrium the quantities $\min \left\{D_{i}(p), \bar{q}\right\}$ for some well chosen $\bar{q}$. But as no type $i$ can purchase more than $D_{i}(p)$ in total, it must be that each market maker $k$ sells the same quantity $\bar{q}$ to all the insider's types who trade and, therefore, that the aggregate demands of all those types is the same. However, by Assumption ID- $U, D_{I}(p)>D_{I-1}(p)$ if trade takes place in equilibrium. Hence the following result holds.

Proposition 4. Suppose that market makers have identical profit functions $v_{i}$ and consider a price $p$ such that $v_{i}(q, p q)$ is strictly concave in $q$ for all $i$. Then if trade takes place at price $p$ in a linear-pricing equilibrium with nondecreasing individual quantities of the arbitrary-tariff game, then only type I can trade and, if $D_{I}(p)>0$, then $\left\{D_{I}(p) / K\right\}=\arg \max \left\{v_{I}(p, p q): q\right\}$ and each market maker sells $D_{I}(p) / K$ to type I only.

The endogenous condition on profit functions in Proposition 4 is satisfied if Assumption C- $v$ holds, as in Theorem 1(ii), so that market makers are risk-neutral with respect to transfers but have identical strictly convex costs Roll (1984). It is also satisfied if market makers are risk-averse, as when $v_{i}(q, t) \equiv v\left(t-c_{i} q\right)$ for some strictly concave von Neumann-Morgenstern utility function $v$ (Stoll 1978, Ho and Stoll 1981, 1983).

In the single-type case, Proposition 4 states that any equilibrium is competitive in the usual sense: first, the insider purchases her optimal demand $D_{1}(p)$ at price $p$; next, the market makers maximize their profit $v_{1}(q, p q)$ at price $p$; finally, the equilibrium price $p$ equalizes the insider's demand and the sum of the market makers' supplies. Equilibrium outcomes are then first-best efficient.

With multiple types, the unique candidate equilibrium outcome remains that which would prevail in an economy populated by type $I$ only. A necessary condition for equilibrium is thus that all types $i<I$ purchase a zero quantity at the equilibrium price $p$. This market-breakdown outcome is similar to the one characterized in Proposition 3 when market makers have linear costs, and the conditions for the existence of an equilibrium are very restrictive in this case as well.

A novel insight of Proposition 4 is that the market breaks down whether or not the environment features common values. To illustrate this point, consider, for instance,

\footnotetext{
${ }^{8}$ Intuitively, for each $\bar{q}$, market maker $k$ can place a limit order at price $p^{\prime}<p$ with maximum quantity $\bar{q}$. As he offers the lowest price, he sells a quantity $\min \left\{D_{i}\left(p^{\prime}\right), \bar{q}\right\}$ to each type $i$. Because demand and profit functions are continuous, by making $p^{\prime}$ go to $p$, market maker $k$ can claim the expected profit associated to the quantities (14).
} 
the case of strictly convex costs (Assumption C- $v$ ) and suppose that the cost function is the same for each type-that is, $c_{i}(q) \equiv c(q)$ for all $i$ and $q$-whereas demands $D_{i}(p)$ are strictly increasing in $i$. As any market maker's profit $t-c(q)$ on a given trade $(q, t)$ does not depend on the insider's type, we are in a private-value setting, so that the only risk market makers are exposed to is to face a high-demand type. Still, oligopolistic competition threatens the existence of equilibria: each market maker wants to reduce his maximum supply if the equilibrium price is too low, but a high equilibrium price strengthens the competition to attract lower types. Overall, competition is strong enough to imply that, in equilibrium, at most one type can trade.

\section{OTHER EQUILIBRIUM OUTCOMES}

To complete the proof of Theorems 1 and 2, there remains to show that focusing on equilibria with nondecreasing individual quantities involves no loss of generality; that is, we can turn any equilibrium with convex tariffs into an equilibrium with the same tariffs and the same expected payoffs for all players, but now with nondecreasing individual quantities. This result holds both in the arbitrary-tariff game and in the convex-tariff game. The proof is actually very general and relies only on a property specifying that, in a certain sense, allocations with nondecreasing individual quantities are efficient.

To understand this point, observe that market makers have to choose their tariffs before demand realizes. Because, by Assumptions SC- $U$ and SC- $v$, high-demand types are more costly to serve, how the market makers share the resulting aggregate risk becomes a central question, which motivates the following analysis. Given a profile $\left(t^{1}, \ldots, t^{K}\right)$ of convex tariffs, recall that each type has a uniquely determined aggregate trade $\left(Q_{i}, T_{i}\right)$. An allocation $\left(q_{1}^{1}, \ldots, q_{1}^{K}, \ldots, q_{I}^{1}, \ldots, q_{I}^{K}\right)$ is feasible if

$$
\sum_{k} q_{i}^{k}=Q_{i} \quad \text { and } \quad \sum_{k} t^{k}\left(q_{i}^{k}\right)=T_{i}, \quad i=1, \ldots, I .
$$

That is, a feasible allocation describes a best response of the insider to the tariffs $\left(t^{1}, \ldots, t^{K}\right)$. A feasible allocation is efficient if it is not Pareto-dominated by any other feasible allocation from the market makers' viewpoint; that is, there is no best response of the insider that yields at least as high an expected profit to each market maker and a strictly higher expected profit to at least one market maker. Our analysis relies on the following property.

Property E. For any profile of convex tariffs $\left(t^{1}, \ldots, t^{K}\right)$, there exists an efficient allocation with nondecreasing individual quantities.

This property is reminiscent of the mutuality principle in risk-sharing (Borch 1962): efficiency requires that any increase in the aggregate quantity to be shared should translate into an increase in individual quantities. However, in our setting, the market makers' profit functions can be state-dependent because they can directly depend on the insider's type. Moreover, the convexity of the tariffs $\left(t^{1}, \ldots, t^{K}\right)$ can make the profits 
$v_{i}^{k}\left(q, t^{k}(q)\right)$ nonconcave in $q$. To bypass these difficulties, we have to impose more restrictions on the market maker's profit functions than in the previous sections. Notable special cases are Assumptions L- $v$ and C- $v$ used in Theorems 1 and 2, as the following result shows. ${ }^{9}$

Lemma 5. Suppose that all market makers have identical quasilinear profit functions

$$
v_{i}^{k}(q, t) \equiv t-c_{i}(q),
$$

where the cost $c_{i}(q)$ is convex in $q$ for all $i$. Then Property $E$ is satisfied.

We can now turn to the study of an arbitrary equilibrium $\left(t^{1}, \ldots, t^{K}, s\right)$ with convex tariffs of either the arbitrary-tariff or the convex-tariff game. Let $v^{k}$ be the equilibrium expected profit of market maker $k$. Depending on the game under study, Lemma 2 and Lemma 3 provide lower bounds $V^{k}\left(t^{-k}\right)$ and $V_{\text {co }}^{k}\left(t^{-k}\right)$ for $v^{k}$, respectively. We can build another lower bound by adding to problems (8) and (11) the additional constraint that the transfers to market maker $k$ be computed according to the equilibrium tariff $t^{k}$; let the corresponding value be $\underline{V}^{k}\left(t^{1}, \ldots, t^{K}\right)$. Therefore,

$$
v^{k} \geq \underline{V}^{k}\left(t^{1}, \ldots, t^{K}\right), \quad k=1, \ldots, K .
$$

In addition, if Property $\mathrm{E}$ is satisfied, then given the tariffs $\left(t^{1}, \ldots, t^{K}\right)$, there exists an efficient allocation $\left(q_{1}^{1}, \ldots, q_{1}^{K}, \ldots, q_{I}^{1}, \ldots, q_{I}^{K}\right)$ with nondecreasing individual quantities. In particular, for each $k$, the quantities $\left(q_{1}^{k}, \ldots, q_{I}^{k}\right)$ satisfy the constraints in the problem that defines $\underline{V}^{k}\left(t^{1}, \ldots, t^{K}\right)$. This implies

$$
\underline{V}^{k}\left(t^{1}, \ldots, t^{K}\right) \geq \sum_{i} m_{i} v_{i}^{k}\left(q_{i}^{k}, t^{k}\left(q_{i}^{k}\right)\right), \quad k=1, \ldots, K .
$$

Chaining inequalities (16) and (17), we obtain that each market maker $k$ 's equilibrium expected profit is no less than his expected profit from the allocation $\left(q_{1}^{1}, \ldots, q_{1}^{K}, \ldots\right.$, $\left.q_{I}^{1}, \ldots, q_{I}^{K}\right)$. Because this allocation is efficient, this is impossible unless all inequalities (16) and (17) are in fact equalities. As a result,

$$
v^{k}=\sum_{i} m_{i} v_{i}^{k}\left(q_{i}^{k}, t^{k}\left(q_{i}^{k}\right)\right), \quad k=1, \ldots, K
$$

We now build an equilibrium that implements the efficient allocation $\left(q_{1}^{1}, \ldots, q_{1}^{K}, \ldots\right.$, $\left.q_{I}^{1}, \ldots, q_{I}^{K}\right)$. Let us define $s^{*}$ as the insider's strategy that selects this allocation if the market makers post the tariffs $\left(t^{1}, \ldots, t^{K}\right)$; otherwise, let $s^{*}$ select the same quantities as $s$. We claim that $\left(t^{1}, \ldots, t^{K}, s^{*}\right)$ is an equilibrium. First, the insider plays a best response to any tariff profile. Moreover, in the initial equilibrium $\left(t^{1}, \ldots, t^{K}, s\right)$, no market

\footnotetext{
${ }^{9}$ We can more generally show that Lemma 5 holds for market makers with heterogenous cost functions $c_{i}^{k}$, the derivatives of which satisfy $c_{i}^{k \prime}=g_{i} \circ a^{k}$, where $g_{i}$ is strictly increasing and $a^{k}$ is nondecreasing. This, in particular, allows us to handle the case of market makers with heterogeneous inventories, where $c_{i}^{k}(q) \equiv c_{i}\left(q-I^{k}\right)$ for some given inventories $I^{k}$.
} 
maker has a profitable deviation. Hence, for each $k$ and for any tariff $\hat{t}^{k} \neq t^{k},{ }^{10}$ we have

$$
v^{k} \geq \sum_{i} m_{i} v_{i}^{k}\left(s_{i}^{k}\left(\hat{t}^{k}, t^{-k}\right), \hat{t}^{k}\left(s_{i}^{k}\left(\hat{t}^{k}, t^{-k}\right)\right)\right) .
$$

From (18) and the definition of $s^{*}$, this can be rewritten as

$$
\sum_{i} m_{i} v_{i}^{k}\left(s_{i}^{* k}\left(t^{k}, t^{-k}\right), t^{k}\left(s_{i}^{* k}\left(t^{k}, t^{-k}\right)\right)\right) \geq \sum_{i} m_{i} v_{i}^{k}\left(s_{i}^{* k}\left(\hat{t}^{k}, t^{-k}\right), \hat{t}^{k}\left(s_{i}^{* k}\left(\hat{t}^{k}, t^{-k}\right)\right)\right),
$$

which expresses that market maker $k$ has no profitable deviation when the other market makers post tariffs $t^{-k}$ and the insider plays her best response $s^{*}$. Hence the following result holds.

Proposition 5. Suppose that Property E is satisfied and that in the convex-tariff game, the insider has quasilinear utility and the market makers have linear costs. Then if $\left(t^{1}, \ldots, t^{K}, s\right)$ is an equilibrium with convex tariffs of either the arbitrary-tariff or the convex-tariff game, there exists a strategy $s^{*}$ for the insider such that $\left(t^{1}, \ldots, t^{K}, s^{*}\right)$ is an equilibrium with nondecreasing individual quantities that yields the same expected profit to each market maker as $\left(t^{1}, \ldots, t^{K}, s\right)$.

We can now complete the proof of Theorems 1 and 2. By Lemma 5, Property E is satisfied under Assumptions L- $v$ and C- $v$. It then follows from Proposition 5 that we can turn any equilibrium with convex tariffs into an equilibrium with the same tariffs and nondecreasing individual quantities. Propositions 1 and 2 then imply that all equilibria with convex tariffs must involve linear pricing, and Theorems 1 and 2 follow as immediate consequences of Propositions 3 and 4. A byproduct of Proposition 5 is that equilibria with convex tariffs, when they exist, support allocations that are efficient from the market makers' viewpoint.

\section{NECESSARY AND SUFFICIENT CONDITIONS FOR EQUILIBRIUM}

We now provide necessary and sufficient conditions for the existence of equilibria with convex tariffs. To do so, we first define a notion of marginal rates of substitution for the insider that does not require differentiability. Specifically, let $\tau_{i}(Q, T)$ be the supremum of the set of prices $p$ such that

$$
U_{i}(Q, T)<\max \left\{U_{i}\left(Q+Q^{\prime}, T+p Q^{\prime}\right): Q^{\prime} \geq 0\right\} .
$$

That is, $\tau_{i}(Q, T)$ is type $i$ 's willingness to increase his purchases at $(Q, T)$. In line with Attar et al. (2017), we impose the intuitive fanning-out condition that for any given transfer $T$, an increase in the quantity $Q$ does not increase this willingness to pay.

Assumption FO- $U$. For all $i$ and $T, \tau_{i}(Q, T)$ is nonincreasing in $Q$.

\footnotetext{
${ }^{10}$ In the convex-tariff game, $\hat{t}^{k}$ must additionally be convex.
} 
It should be noted that Assumption FO- $U$ automatically holds under Assumption QL- $U$. More generally, Assumption FO- $U$ holds under many alternative specifications, allowing for risk aversion and wealth effects. An important implication of Assumption FO- $U$ is the following property.

Property P. For all $i, Q$, and $T \geq 0$,

$$
U_{i}(Q, T) \geq U_{i}(0,0) \quad \text { implies } \tau_{i}(Q, T) \leq \tau_{i}(0,0) .
$$

Indeed, from any point $(Q, T)$ such that $T \geq 0$, we can draw an indifference curve for $U_{i}$ that necessarily crosses the $Q$-axis from above at the right of $(0,0)$. At this point, the marginal rate of substitution is not higher than at $(0,0)$ by Assumption FO- $U$, and it is not lower than at $(Q, T)$ by quasiconcavity of $U_{i}$. This proves Property $\mathrm{P}$.

We also impose the following Inada condition.

Assumption I- $U$. For all $i, Q, T$, and $p>0$,

$$
\arg \max \left\{U_{i}\left(Q+Q^{\prime}, T+p Q^{\prime}\right): Q^{\prime} \geq 0\right\}<\infty .
$$

Under Assumption I- $U$, the demand $D_{i}(p)$ of type $i$ at any strictly positive price $p$ is finite; in particular, the demands in Theorems 1 and 2 are well defined, which is clearly a necessary condition for the existence of an equilibrium.

Let us now turn to the market makers' costs. We give a unified treatment of the linear-cost case (Assumption L- $v$ ) and of the convex-cost case (Assumption C- $v$ ), generically denoting the cost of serving type $i$ by the function $c_{i}(q)$, with $c_{i}(q) \equiv c_{i} q$ in the linear-cost case. Define $i^{*}$ as being equal to $I$ in the convex-cost case and being equal to the lowest $i$ such that $c_{i}=c_{I}$ in the linear-cost case. According to Theorems 1 and 2, in equilibrium, types $i<i^{*}$ do not trade and types $i \geq i^{*}$ purchase their demands $D_{i}(p)$ at some price $p \in \partial c_{I}\left(D_{I}(p) / K\right)$ equal to $c_{I}$ in the linear-cost case. Thus the relevant measure of costs is, for types $i<i^{*}$, their marginal costs $\partial^{+} c_{i}(0)$ at 0 and, for types $i \geq i^{*}$, the price $p$. The upper-tail expectation of these costs, conditional on the insider's type being at least $i$, is thus

$$
\bar{c}_{i}(p) \equiv \frac{\sum_{i^{*}>j \geq i} m_{j} \partial^{+} c_{j}(0)+p \sum_{j \geq i^{*}, i} m_{j}}{\sum_{j \geq i} m_{j}},
$$

with $\sum_{\varnothing}=0$ by convention. The central theorem of this section provides necessary and sufficient conditions for equilibria with convex tariffs.

THeOREм 3. Suppose that the fanning-out and Inada conditions are satisfied (Assumptions FO-U and I-U). Additionally, make the following suppositions:

(i) In the arbitrary-tariff game, market makers have linear costs (Assumption L-v) or convex costs (Assumption C-v). 
(ii) In the convex-tariff game, the insider has quasilinear utility (Assumption QL-U) and market makers have linear costs (Assumption L-v).

Then the arbitrary-tariff and the convex-tariff games have a pure-strategy equilibrium with convex tariffs if and only if, for some $p$ such that $p \in \partial c_{I}\left(D_{I}(p) / K\right)$,

$$
i<i^{*} \quad \text { implies } \tau_{i}(0,0) \leq \bar{c}_{i}(p) .
$$

An equilibrium can then be supported by each market maker posting the linear tariff

$$
t(q) \equiv p q, \quad q \in\left[0, \frac{1}{K-1} D_{I}(p)\right]
$$

and each type $i$ splitting her demand $D_{i}(p)$ equally among the $K$ market makers.

The intuition for this result is twofold. As for types $i \geq i^{*}$, the quantities they purchase must be efficiently allocated among the market makers, as shown in Section 6 . Under linear pricing, this implies that each market maker sells an element of his competitive supply at price $p$. Hence no market maker can increase his expected profit from trading with types $i \geq i^{*}$, because he already sells his most preferred quantities at price $p$ to them. As for types $i<i^{*}$, the key idea is that if a trade attracts any such type $i$, then it also attracts all types $j>i$ by Property SC- $z$. Therefore, the relevant notion of marginal cost is the upper-tail expectation of costs $\bar{c}_{i}(p)$. Condition (20) then ensures that this trade takes place at a price strictly below $\bar{c}_{i}(p)$ and thus, in expectation, makes a loss.

Overall, these results confirm that equilibria exist only under exceptional circumstances, in which only the types with the highest marginal cost are willing to trade; in that case, the equilibrium coincides with a competitive equilibrium of a fictitious economy populated by those types only. Consider for instance the linear-cost case. In the pure private-value case, where $c_{i}=c_{I}$ for all $i$, conditions (20) are emptily satisfied as $i^{*}=1$. Hence an equilibrium always exists, in which each type efficiently trades at marginal cost $c_{I}$; the equilibrium allocation is first-best efficient. By contrast, in the pure common-value case, where $c_{i}<c_{I}$ for all $i<I$, conditions (20) are very demanding: in an equilibrium in which type $I$ trades, we must have $\tau_{i}(0,0) \leq \mathbf{E}\left[c_{j} \mid j \geq i\right]$ for all $i<I$ and $\tau_{I}(0,0)>c_{I}$. That is, type $I$ must have preferences that are sufficiently different from those of types $i<I$. In particular, when we let the number of types grow large so as to approximate an interval, it is increasingly difficult and, eventually, impossible to satisfy these conditions.

In the constructed equilibrium, each market maker offers a continuum of trades by placing a limit order allowing the insider to purchase any quantity up to $D_{I}(p) /(K-1)$ at price $p$. This first ensures that no market maker is indispensable for providing type $I$ with her demand $D_{I}(p)$ at price $p$, which, as we have seen, is a necessary condition for equilibrium. This also ensures that the insider's indirect utility functions satisfy Property SC- $z$. As a result, if a market maker deviates, the insider has a best response in which she purchases nondecreasing quantities from him. In this way, cream-skimming deviations are blocked: any attempt to propose a profitable trade to any type with a marginal cost less than the market price fails because, given the limit orders placed by 
the other market makers, this trade also attracts all the higher types. Thus the continuum of trades offered by each market maker at price $p$ serve as latent contracts that prevent his competitors from deviating.

\section{Discussion}

In this section, we put our findings in perspective and relate them to the literature.

$a$. The model we use is standard-we may even say canonical. The restriction to equilibria with convex tariffs is motivated by our focus on discriminatory pricing in a limitorder book. We allow for arbitrary discrete distributions for the insider's type and for a rich set of convex preferences for the insider and the market makers. The strict convexity of the insider's preferences ensures that her aggregate demand for the asset continuously responds to price variations. This captures the idea that she has both informational and hedging motives for trade, as in Glosten (1989), Biais et al. (2000), and Back and Baruch (2013). News traders, that is, insiders who are perfectly informed of the liquidation value of the asset and trade only on the basis of this information, as in Dennert (1993) or Baruch and Glosten (2017), are a limiting case of our analysis. Finally, the model is fully strategic in that, unlike much of the market-microstructure literature, it does not rely on noise traders who are insensitive to prices.

$b$. A key insight of our analysis is that no market maker is indispensable for providing the insider with her aggregate equilibrium trades; otherwise, he would have an incentive to raise his price on the additional trade he makes with some type. We use standard mechanism-design techniques (Lemma 2) or standard price-theory arguments (Lemma 3) to show that he can do so without reducing his expected profit on the other types. The discreteness of the set of types is crucial for the precise targeting required by this logic. As we have seen, it follows that the insider's downward local constraints must be binding when suitably expressed in terms of her indirect utility functions. This, in turn, implies that equilibrium tariffs must be linear. By contrast, in models with a continuum of types, Biais et al. (2000) and Back and Baruch (2013) show how to construct a symmetric equilibrium in which each market maker posts a strictly convex tariff. Each market maker is then indispensable as each type has a unique best response; in particular, tie breaking is no longer a relevant issue. Although strictly convex tariffs are not consistent with equilibrium in the discrete-type case-as the consideration of the single-type case readily shows-they can be sustained in the continuous-type case because a local change in the tariff affects the behavior of all neighboring types. To illustrate this point, suppose that a market maker deviates by proposing, instead of a portion of his strictly convex equilibrium tariff, the corresponding chord. This would increase his expected profit if the insider's behavior remained the same. But such a change raises (lowers) the marginal price for relatively low-cost (high-cost) types who would choose trades in this portion of the tariff. As a result, under common values, trades change in an unfavorable way for the deviating market maker. This last effect is reinforced when the insider simultaneously trades with several market makers, as any increase in the quantity she purchases from a market maker is compensated by a reduction in the quan- 
tity she purchases from the others. The equilibrium in Biais et al. (2000) and Back and Baruch (2013) strikes a delicate balance between these two effects. This is why their construction requires complex restrictions on the distribution of the insider's type and on the expected value of the asset conditional on her type. By contrast, our results hold for general discrete-type environments and do not require such restrictions.

c. A key feature of candidate equilibria of our model is that market makers want to hedge against the adverse-selection risk or, when they have strictly convex costs, against the high-demand risk. A strictly convex tariff would perform this role by making highcost and, therefore, high-demand types trade at a higher marginal price than low-cost and, therefore, low-demand types. However, whereas such tariffs naturally arise in the continuous-type environments of Glosten (1994), Biais et al. (2000), or Back and Baruch (2013), they are ruled out in our discrete-type environment as any equilibrium must feature linear pricing. Simpler tariffs such as limit orders then play a key role. We have shown that in a situation in which all market makers but one post linear tariffs, placing a well chosen limit order is the optimal way for the remaining market maker to reduce his exposure to the adverse-selection and high-demand risks. However, a crucial finding is that in spite of their popularity, limit orders are consistent with equilibrium only under exceptional circumstances. This is because the equilibrium price must be high enough to convince market makers to serve high-cost types. But such a high price gives each market maker an incentive to serve all the demand emanating from low-cost types, which is inconsistent with equilibrium unless these types do not want to trade at that price. This confirms and extends in a radical way earlier results by Attar et al. (2014), who show in the two-type case that at most one type trades in any pure-strategy equilibrium of the arbitrary-tariff game. Their result, however, is somehow more general as they do not require that equilibrium tariffs be convex: this could be relevant for the analysis of competition on less regulated markets, such as over-the-counter markets, in which trading is bilateral and fully nonexclusive. It is an open and difficult question to generalize the results of the present paper to candidate equilibria with nonconvex tariffs of the arbitrary-tariff game when there are more than two types. The main obstacle is that Property SC- $z$ is no longer necessarily satisfied. As a result, a trade that attracts some type need not attract all the higher types.

$d$. In light of our analysis, the strategic foundations of the discriminatory limit-order book appear problematic: equilibria fail to exist when there are sufficiently many types with similar preferences, as when we approximate the continuous sets of types postulated by Biais et al. (2000) or Back and Baruch (2013). Given the positive existence results derived by these authors, the pure-strategy-equilibrium correspondence thus fails to be lower hemicontinuous when we move from discrete-type models to continuous-type models. Our analysis admittedly leaves open the possibility that equilibria with convex tariffs of continuous-type models could be approximated by equilibria with nonconvex tariffs of a sequence of discrete-type models. As pointed out above, however, such a construction is likely to be complex. Moreover, these putative equilibria could not be interpreted as describing the functioning of a discriminatory limit-order book. The search for strategic foundations seems even more problematic if market makers have strictly 
convex costs, as the market then break downs or an equilibrium fails to exist even under private values.

\section{9. $\varepsilon$-EQUILIBRIA}

Requiring an exact strategic foundation for the discriminatory limit-order book may be asking too much. In this section, we instead focus on approximate equilibria that can be sustained when we converge to two limiting cases of our model. We first study the competitive limit obtained when there is a fixed number of types but the number of market makers goes to infinity. We next study the continuous limit obtained when there is a fixed number of market makers but the number of types goes to infinity so as to approximate an interval.

\subsection{The competitive limit}

A natural candidate for describing the discriminatory limit-order book as a whole is the competitive tariff proposed by Glosten (1994), preceded by contributions of Jaynes (1978) and Hellwig (1988). This tariff, to be described below, is by construction entryproof. ${ }^{11}$ However, according to our analysis, it cannot be sustained as an equilibrium outcome of either the arbitrary-tariff or the convex-tariff game: because each market maker trading with low-cost insiders is indispensable for providing these types with their optimal trades along this tariff, he has a profitable deviation. ${ }^{12}$ A natural question is how much expected profit he would forego by not playing a best response. The answer turns out to depend on the market structure, that is, on how many market makers there are.

To illustrate this point, suppose that the insider has quasilinear utility (Assumption QL- $U$ ), with twice differentiable utility functions $u_{i}$, and that the market makers have linear costs (Assumption L- $v$ ). We consider the pure common-value case where the $\operatorname{cost} c_{i}$ is strictly increasing in the insider's type $i$. Analogous to (19), for each $i$, let

$$
\bar{c}_{i} \equiv \mathbf{E}\left[c_{j} \mid j \geq i\right]=\frac{\sum_{j \geq i} m_{j} c_{j}}{\sum_{j \geq i} m_{j}}
$$

be the upper-tail expectation of these costs, conditional on the insider's type being at least $i$. Under quasilinear utility, the Jaynes-Hellwig-Glosten (JHG) allocation is recursively defined by $\left(Q_{0}^{*}, T_{0}^{*}\right) \equiv(0,0)$ and

$$
\begin{aligned}
& Q_{i}^{*} \equiv \arg \max \left\{u_{i}(Q)-\bar{c}_{i} Q: Q \geq Q_{i-1}^{*}\right\} \\
& T_{i}^{*} \equiv T_{i-1}^{*}+\bar{c}_{i}\left(Q_{i}^{*}-Q_{i-1}^{*}\right), \quad i=1, \ldots, I .
\end{aligned}
$$

\footnotetext{
${ }^{11}$ This is shown by Glosten (1994) in a model in which the insider has quasilinear utility and types are continuously distributed. Attar et al. (2016) provide a simple argument that dispenses with the quasilinearity assumption in the two-type case and Attar et al. (2017) provide a general result for arbitrary distributions of types under weak conditions on the insider's preferences.

${ }^{12}$ We exploited this logic in the proof of Propositions 1 and 2.
} 
This allocation is well defined, for instance, when the Inada condition $\lim _{Q \rightarrow \infty} u_{i}^{\prime}(Q)=0$ is satisfied for all $i$. The relevant first-order condition for type $i$ is

$$
u_{i}^{\prime}\left(Q_{i}^{*}\right) \leq \bar{c}_{i}, \quad \text { with equality if } Q_{i}^{*}>Q_{i-1}^{*} .
$$

There exists an essentially unique convex tariff implementing the JHG allocation, namely, the JHG tariff recursively defined by $T^{*}(0) \equiv 0$ and

$$
T^{*}(Q) \equiv T^{*}\left(Q_{i-1}^{*}\right)+\bar{c}_{i}\left(Q-Q_{i-1}^{*}\right), \quad i=1, \ldots, I, Q \in\left(Q_{i-1}^{*}, Q_{i}^{*}\right] .
$$

The JHG tariff is competitive in the sense that any marginal quantity is priced at the expected cost of serving the types who purchase it, which can be interpreted as a marginal version of Akerlof (1970) pricing.

Let us now return to the arbitrary-tariff game, with a finite number $K$ of market makers. In this context, the JHG tariff can be implemented by letting each market maker place $I$ limit orders with maximum quantities $\left(Q_{i}^{*}-Q_{i-1}^{*}\right) / K$ and prices $\bar{c}_{i}$, which amounts to posting the convex tariff $T^{*}(K q) / K$. However, in this implementation, each market maker $k$ is indispensable for providing $T^{*}$ in the aggregate and, therefore, has a profitable deviation. We now identify an upper bound for his expected gain from deviating.

Given that the market makers other than $k$ all post the convex tariff $T^{*}(K q) / K$, the resulting aggregate tariff is, according to (2.4), given by

$$
T^{*-k}\left(Q^{-k}\right) \equiv \frac{K-1}{K} T^{*}\left(\frac{K}{K-1} Q^{-k}\right) .
$$

Market maker $k$ thus faces an insider whose indirect utility from trading $(q, t)$ with him is $z_{i}^{*-k}(q, t) \equiv \zeta_{i}^{*-k}(q)-t$, where

$$
\zeta_{i}^{*-k}(q) \equiv \max \left\{u_{i}\left(q+Q^{-k}\right)-T^{*-k}\left(Q^{-k}\right): Q^{-k} \geq 0\right\} .
$$

As $T^{*}$ and, hence, $T^{*-k}$, are convex, Property SC- $z$ is satisfied. It is easy to check from (23) and (24) and the definition of $T^{*}$ that the functions $\zeta_{i}^{*-k}$ are strictly concave, with

$$
\max \left\{\zeta_{i}^{*-k}(q)-\bar{c}_{i} q: q \geq 0\right\}=u_{i}\left(Q_{i}^{*}\right)-\frac{K-1}{K} T_{i}^{*}-\frac{1}{K} \bar{c}_{i} Q_{i}^{*},
$$

where the maximum in (25) is attained for $q=Q_{i}^{*} / K$.

To obtain an upper bound for market maker $k$ 's expected gain from deviating, there is no loss of generality in letting him offer a menu $\left\{\left(q_{i}, t_{i}\right): i=0, \ldots, I\right\}$ designed so that each type $i$ selects the trade $\left(q_{i}, t_{i}\right)$. Because Property SC- $z$ is satisfied, we can assume that the insider selects a best response in which she purchases nondecreasing quantities from market maker $k$, that is, $q_{i} \geq q_{i-1}$ for all $i$. Using a summation by parts, the resulting expected profit can be rewritten as

$$
\sum_{i}\left(\sum_{j \geq i} m_{j}\right)\left[t_{i}-t_{i-1}-\bar{c}_{i}\left(q_{i}-q_{i-1}\right)\right] .
$$


A necessary condition for each type $i$ to trade $\left(q_{i}, t_{i}\right)$ with market maker $k$ is (7), which, under quasilinear utility, amounts to

$$
t_{i}-t_{i-1} \leq \zeta_{i}^{*-k}\left(q_{i}\right)-\zeta_{i}^{*-k}\left(q_{i-1}\right), \quad i=1, \ldots, I .
$$

An upper bound for market maker $k$ 's expected gain from deviating is thus

$$
\begin{aligned}
& \sum_{i}\left(\sum_{j \geq i} m_{j}\right) \max \left\{\zeta_{i}^{*-k}\left(q_{i-1}+q\right)-\zeta_{i}^{*-k}\left(q_{i-1}\right)-\bar{c}_{i} q: q_{i-1} \geq 0, q \geq 0\right\} \\
& \quad \leq \sum_{i}\left(\sum_{j \geq i} m_{j}\right) \max \left\{\zeta_{i}^{*-k}(q)-\zeta_{i}^{*-k}(0)-\bar{c}_{i} q: q \geq 0\right\} \\
& \quad=\sum_{i}\left(\sum_{j \geq i} m_{j}\right)\left[u_{i}\left(Q_{i}^{*}\right)-\frac{K-1}{K} T_{i}^{*}-\frac{1}{K} \bar{c}_{i} Q_{i}^{*}-\zeta_{i}^{*-k}(0)\right] \\
& \quad \leq \sum_{i}\left(\sum_{j \geq i} m_{j}\right)\left[u_{i}\left(Q_{i}^{*}\right)-u_{i}\left(\frac{K-1}{K} Q_{i}^{*}\right)-\frac{1}{K} \bar{c}_{i} Q_{i}^{*}\right] \\
& \quad=\sum_{i}\left(\sum_{j \geq i} m_{j}\right)\left\{\frac{1}{K}\left[u_{i}^{\prime}\left(Q_{i}^{*}\right)-\bar{c}_{i}\right] Q_{i}^{*}-\frac{1}{2 K^{2}} u_{i}^{\prime \prime}\left(Q_{i}^{*}\right)\left(Q_{i}^{*}\right)^{2}+o\left(\frac{1}{K^{2}}\right)\right\} \\
& \quad \leq \sum_{i}\left(\sum_{j \geq i} m_{j}\right)\left[-\frac{1}{2 K^{2}} u_{i}^{\prime \prime}\left(Q_{i}^{*}\right)\left(Q_{i}^{*}\right)^{2}+o\left(\frac{1}{K^{2}}\right)\right] \\
& \quad=O\left(\frac{1}{K^{2}}\right),
\end{aligned}
$$

where the first inequality follows from the concavity of the functions $\zeta_{i}^{*-k}$, the first equality follows from (25), the second inequality follows the fact that each type $i$ can always trade $\left((K-1) Q_{i}^{*} / K,(K-1) T_{i}^{*} / K\right)$ with the market makers other than $k$, the second equality follows from a Taylor-Young expansion, and the third inequality follows from the first-order condition (22). We obtain that in the arbitrary-tariff game with $K$ market makers, if the market makers other than $k$ post the tariff $T^{*}(K q) / K$, the maximum expected gain for market maker $k$ from deviating to another tariff vanishes at rate $1 / K^{2}$ as $K$ goes to infinity. We can thus rationalize the JHG allocation as an $O\left(1 / K^{2}\right)$ equilibrium outcome of a game with a large number of market makers.

\subsection{The continuous limit}

In the last section, we examined what happens when we let the number of market makers grow large, holding the number of types fixed. We now explore the dual scenario in which we let the number of types grow large, holding the number of market makers fixed. In the continuous-type case, Biais et al. (2000) show that, under certain assumptions on primitives, there exists a symmetric equilibrium of the arbitrary-tariff game in which all market makers post the same strictly convex tariff. However, according to our analysis, this tariff is not part of an equilibrium of any discrete-type version of this game: 
because each market maker wants to make the insider's downward local constraints bind, he has a profitable deviation. A natural question is how much profits he would forego by not playing a best response. The answer turns out to depend on the richness of the set of types, that is, on how closely it approximates an interval.

To illustrate this point, it is useful to first recall how Biais et al. (2000) proceed to solve the arbitrary-tariff game. Let the insider's type $\theta$ be distributed over a bounded interval $[\underline{\theta}, \bar{\theta}]$ according to a distribution $F$ with strictly positive density $f$. Type $\theta$ 's utility function is $U(Q, T, \theta) \equiv u(Q, \theta)-T$ and the market makers' cost of serving type $\theta$ is $c(\theta) .{ }^{13}$ Now select a market maker $k$ and suppose that all the other market makers post the same strictly convex tariff $t$. Then the resulting aggregate tariff is, according to (2.4), given by

$$
T^{-k}\left(Q^{-k}\right) \equiv(K-1) t\left(\frac{1}{K-1} Q^{-k}\right)
$$

Market maker $k$ thus faces an insider whose indirect utility from trading $(q, t)$ with him is $z^{-k}(q, t, \theta) \equiv \zeta^{-k}(q, \theta)-t$, where

$$
\zeta^{-k}(q, \theta) \equiv \max \left\{u\left(q+Q^{-k}, \theta\right)-T^{-k}\left(Q^{-k}\right): Q^{-k} \geq 0\right\} .
$$

As $t$ and, hence, $T^{-k}$, are strictly convex, the family of functions $\zeta^{-k}(\cdot, \theta)$ satisfies the strict single-crossing property. Characterizing market maker $k$ 's best response in the arbitrary-tariff game then reduces to a standard screening problem, namely, that of finding a menu of trades $\{(\chi(\theta), \tau(\theta)): \theta \in[\underline{\theta}, \bar{\theta}]\}$ that maximizes his expected profit

$$
\int_{\underline{\theta}}^{\bar{\theta}}[\tau(\theta)-c(\theta) \chi(\theta)] f(\theta) \mathrm{d} \theta,
$$

subject to the incentive-compatibility constraints

$$
\zeta^{-k}(\chi(\theta), \theta)-\tau(\theta) \geq \zeta^{-k}\left(\chi\left(\theta^{\prime}\right), \theta\right)-\tau\left(\theta^{\prime}\right), \quad\left(\theta, \theta^{\prime}\right) \in[\underline{\theta}, \bar{\theta}] \times[\underline{\theta}, \bar{\theta}]
$$

and the participation constraints

$$
\zeta^{-k}(\chi(\theta), \theta)-\tau(\theta) \geq \zeta^{-k}(0, \theta), \quad \theta \in[\underline{\theta}, \bar{\theta}] .
$$

Using standard techniques, we obtain that characterizing market maker $k$ 's best response in the continuous-type arbitrary-tariff game amounts to maximizing

$$
\int_{\underline{\theta}}^{\bar{\theta}}\left[\zeta^{-k}(\chi(\theta), \theta)-c(\theta) \chi(\theta)-\frac{1-F(\theta)}{f(\theta)} \frac{\partial \zeta^{-k}}{\partial \theta}(\chi(\theta), \theta)\right] f(\theta) \mathrm{d} \theta-\zeta^{-k}(0, \underline{\theta})
$$

over all nondecreasing quantity schedules $\chi$. Biais et al. (2000) provide assumptions on primitives that guarantee the existence of a strictly convex tariff $t^{*}$ that induces indirect utility functions $\zeta^{*-k}$ as in (26) and (27) for $t \equiv t^{*}$, and is such that the solution

\footnotetext{
${ }^{13}$ Biais et al. (2000) more specifically suppose $u(Q, \theta) \equiv \theta Q-\left(\alpha \sigma^{2} / 2\right) Q^{2}$. We stick to a general notation for the sake of clarity.
} 
$\chi^{*}$ to the problem of maximizing (28) for $\zeta^{-k} \equiv \zeta^{*-k}$ is continuous and implementable by $t^{*}$. Therefore, under these assumptions, there exists a symmetric equilibrium of the arbitrary-tariff game in which all market makers post the tariff $t^{*}$.

We can approximate this construction in our discrete-type setting. Let us choose $I$ discrete types in $[\underline{\theta}, \bar{\theta}]$, regularly spaced for simplicity,

$$
\theta_{i} \equiv \underline{\theta}+\frac{i}{I}(\bar{\theta}-\underline{\theta}), \quad i=1, \ldots, I,
$$

with strictly positive probabilities

$$
m_{i} \equiv F\left(\theta_{i}\right)-F\left(\theta_{i-1}\right), \quad i=1, \ldots, I,
$$

with $\theta_{0} \equiv \underline{\theta}$ by convention. Suppose that all the market makers other than $k$ post the tariff $t^{*}$, so that type $\theta_{i}$ 's indirect utility function is $\zeta^{*-k}\left(\cdot, \theta_{i}\right)$. Again using standard techniques, we obtain that characterizing market maker $k$ 's best response in the discretetype arbitrary-tariff game with $I$ types amounts to maximizing

$\Pi_{I}^{*}(\chi)$

$$
\begin{aligned}
\equiv & \sum_{i=1}^{I} m_{i}\left\{\zeta^{*-k}\left(\chi\left(\theta_{i}\right), \theta_{i}\right)-c\left(\theta_{i}\right) \chi\left(\theta_{i}\right)-\frac{\sum_{j>i} m_{j}}{m_{i}}\left[\zeta^{*-k}\left(\chi\left(\theta_{i}\right), \theta_{i+1}\right)-\zeta^{*-k}\left(\chi\left(\theta_{i}\right), \theta_{i}\right)\right]\right\} \\
& -\zeta^{*-k}(0, \underline{\theta})
\end{aligned}
$$

over all nondecreasing quantity schedules $\chi$. Compared to

$$
\begin{aligned}
\Pi^{*}(\chi) \equiv & \int_{\underline{\theta}}^{\bar{\theta}}\left[\zeta^{*-k}(\chi(\theta), \theta)-c(\theta) \chi(\theta)-\frac{1-F(\theta)}{f(\theta)} \frac{\partial \zeta^{*-k}}{\partial \theta}(\chi(\theta), \theta)\right] f(\theta) \mathrm{d} \theta \\
& -\zeta^{*-k}(0, \underline{\theta})
\end{aligned}
$$

which is (28) for $\zeta^{-k} \equiv \zeta^{*-k}$, the constant of integration in (29) is the same and the sum in (29) is shown to approximate the integral in (30) thanks to the equalities

$$
\begin{aligned}
& m_{i}=\frac{\bar{\theta}-\underline{\theta}}{I} f\left(\theta_{i}\right)+O\left(\frac{1}{I^{2}}\right) \\
& \sum_{j>i} m_{j}=1-F\left(\theta_{i}\right) \\
& \zeta^{*-k}\left(\chi\left(\theta_{i}\right), \theta_{i+1}\right)-\zeta^{*-k}\left(\chi\left(\theta_{i}\right), \theta_{i}\right) \\
& =\frac{\bar{\theta}-\underline{\theta}}{I} \frac{\partial \zeta^{*-k}}{\partial \theta}\left(\chi\left(\theta_{i}\right), \theta_{i}\right)+O\left(\frac{1}{I^{2}}\right), \quad i=1, \ldots, I .
\end{aligned}
$$


The sum in (29) then equals

$$
\frac{\bar{\theta}-\underline{\theta}}{I} \sum_{i=1}^{I}\left[\zeta^{*-k}\left(\chi\left(\theta_{i}\right), \theta_{i}\right)-c\left(\theta_{i}\right) \chi\left(\theta_{i}\right)-\frac{1-F\left(\theta_{i}\right)}{f\left(\theta_{i}\right)} \frac{\partial \zeta^{*-k}}{\partial \theta}\left(\chi\left(\theta_{i}\right), \theta_{i}\right)\right] f\left(\theta_{i}\right)+O\left(\frac{1}{I}\right),
$$

which, under suitable regularity conditions, is the Riemann approximation, with precision $O(1 / I)$, of the integral in (30). These conditions, in turn, imply that this approximation is uniform in $\chi$ as long as we focus on nondecreasing quantity schedules in a uniformly bounded set $X$, which involves no loss of generality; we refer to the Supplemental Material for the required argument. As a result, we have

$$
\sup \left\{\left|\Pi^{*}(\chi)-\Pi_{I}^{*}(\chi)\right|: \chi \in X\right\} \leq O\left(\frac{1}{I}\right) .
$$

Now let $\chi_{I}^{*}$ be a nondecreasing quantity schedule that maximizes (29). Because $\chi^{*}$ is the quantity schedule implemented by the equilibrium tariff $t^{*}$ in the continuous-type arbitrary-tariff game, we have

$$
\Pi^{*}\left(\chi^{*}\right) \geq \Pi^{*}\left(\chi_{I}^{*}\right), \quad I \geq 1 .
$$

Both $\chi^{*}$ and $\chi_{I}^{*}$ belong to $X$. According to (35) and (36), this implies

$$
\Pi_{I}^{*}\left(\chi^{*}\right)+O\left(\frac{1}{I}\right) \geq \Pi_{I}^{*}\left(\chi_{I}^{*}\right)=\max \left\{\Pi_{I}^{*}(\chi): \chi \in X\right\} .
$$

We obtain that in the discrete-type arbitrary-tariff game with $I$ types, if all the market makers other than $k$ post the tariff $t^{*}$, the maximum expected gain for market maker $k$ from deviating to another tariff vanishes at rate $1 / I$ as $I$ goes to infinity. We can thus rationalize the Biais et al. (2000) aggregate allocation as an $O(1 / I)$-equilibrium outcome of a game with a large but finite number of types. Interestingly, this finding is consistent with our analysis of the competitive limit in Section 9.1; indeed, as shown by Biais et al. (2000, Proposition 14), in the continuous-type case, the aggregate equilibrium tariff converges to the JHG tariff when the number of market makers goes to infinity.

\section{Conclusion}

In this paper, we studied the impact of adverse selection on trade when uninformed market makers compete in tariffs to serve an insider whose private information has an arbitrary discrete distribution. Our results strikingly differ from those obtained assuming continuous distributions for the insider's private information. Indeed, pure-strategy equilibria in our model feature linear pricing, whereas the market makers' ability to restrict the quantities they offer at the equilibrium price, using familiar instruments such as limit orders, leads to an extreme form of market breakdown. An implication of our analysis is that pure-strategy equilibria fail to exist in sufficiently fine discretizations of existing continuous-type models, for which pure-strategy equilibria with strictly convex tariffs are known to exist under parametric assumptions on preferences and information. This tension can be relaxed by considering $\varepsilon$-equilibria of discrete-type models 
with a large number of market makers or with a large number of types, leading to the Glosten (1994) allocation and to the Biais et al. (2000) allocation, respectively.

The possibility of precisely targeting types in any discrete-type model and, conversely, the impossibility of doing so in constructed equilibria of continuous-type models, is crucial to understand why the equilibrium correspondence fails to be lower hemicontinuous when we approximate the latter by the former. In any discrete-type model, no market maker can be indispensable in equilibrium; otherwise, he would have an incentive to raise his tariff. Key to this logic is that in candidate equilibria, market makers place non-infinitesimal limit orders to serve a finite number of types. By contrast, in continuous-type models, each market maker is indispensable in equilibrium, yet he has no incentive to raise his tariff. The reason is that in constructed equilibria with strictly convex tariffs, the other market makers place infinitesimal limit orders that act as arbitrarily close substitutes. Which model is more appropriate thus hinges on whether we deem targeting reasonable. In principle, targeting is possible unless a market maker who is issuing a limit order believes that this order can be partially executed to any level up to the maximal quantity. In light of our results, however, it could be argued that, in practice, the expected gains from precisely targeting types are negligible if there are many market makers or many types. We may then consider $\varepsilon$-equilibria as a reasonable description of the functioning of the limit-order book.

An alternative and promising avenue of research would be to characterize mixedstrategy equilibria of the discrete-type model, the existence of which is guaranteed according to known results by Carmona and Fajardo (2009). Preliminary investigations of the two-type case have lead to a robust example of a mixed-strategy equilibrium that exists when the necessary and sufficient conditions for the existence of a pure-strategy equilibrium are not satisfied. Targeting is now impossible because of the strategic uncertainty faced by each market maker regarding the tariffs offered by his competitors. Interestingly, this equilibrium features zero expected profits for the market makers. This contrasts with the mixed-strategy equilibria of Bertrand-Edgeworth oligopoly described by Allen and Hellwig (1986). Besides, this equilibrium bears no apparent relationship with available equilibrium candidates. The Glosten (1994) competitive allocation, in particular, does not emerge when the number of market makers grows large. These findings suggest that further investigations of mixed-strategy equilibria are in order to reach a fuller understanding of the consequences of adverse selection for the functioning of competitive markets.

\section{Appendix}

Proof of Proposition 2. As a preliminary remark, observe that if $\left(t^{1}, \ldots, t^{K}, s\right)$ is an equilibrium with nondecreasing individual quantities of the convex-tariff game, then, by Lemma 3, each market maker $k$ must earn an expected profit $V_{\mathrm{co}}^{k}\left(t^{-k}\right)$ and his equilibrium tariff $t^{k}$ must be a solution to the problem (11) that defines $V_{\mathrm{co}}^{k}\left(t^{-k}\right)$. As shown in Step 1 of the proof of Lemma 3 in the Supplemental Material, $t^{k}$ must then be of the form $t_{p, q}$ and, in particular, must be piecewise linear. The proof consists of four steps.

Step 1. The result is immediate if there is no trade in equilibrium. Thus suppose that trade takes place in equilibrium and let $p \equiv \partial^{-} T\left(Q_{I}\right)$. Any market maker $k$ could 
truncate his tariff at $\underline{s}^{k}(p)$. A best response for the insider consists of purchasing $q_{i}^{k}$ or $\underline{s}^{k}(p)$ from market maker $k$ depending on whether $u_{i}^{\prime}\left(Q_{i}\right)<p$ or $u_{i}^{\prime}\left(Q_{i}\right) \geq p$, overall preserving nondecreasing quantities. We can thus apply Lemma 3 to obtain

$$
\sum_{\left\{i: u_{i}^{\prime}\left(Q_{i}\right) \geq p\right\}} m_{i}\left(p-c_{i}\right)\left[q_{i}^{k}-\underline{s}^{k}(p)\right] \geq 0, \quad k=1, \ldots, K .
$$

Any market maker $k$ could also attract all trades at marginal price $p$ by deviating to a tariff coinciding with $t^{k}$ up to $\underline{s}^{k}(p)$ and offering to sell any quantity between $\underline{s}^{k}(p)$ and $\underline{s}^{k}(p)+\bar{S}(p)-\underline{S}(p)$ at marginal price $p$. A best response for the insider consists of purchasing $q_{i}^{k}$ or $\underline{s}^{k}(p)+Q_{i}-\underline{S}(p)$ from market maker $k$ depending on whether $u_{i}^{\prime}\left(Q_{i}\right)<p$ or $u_{i}^{\prime}\left(Q_{i}\right) \geq p$, overall preserving nondecreasing quantities. We can thus apply Lemma 3 to obtain

$$
\sum_{\left\{i: u_{i}^{\prime}\left(Q_{i}\right) \geq p\right\}} m_{i}\left(p-c_{i}\right)\left[Q_{i}-\underline{S}(p)\right] \leq \sum_{\left\{i: u_{i}^{\prime}\left(Q_{i}\right) \geq p\right\}} m_{i}\left(p-c_{i}\right)\left[q_{i}^{k}-\underline{s}^{k}(p)\right], \quad k=1, \ldots, K .
$$

Summing these inequalities over $k$ in turn yields

$$
\sum_{\left\{i: u_{i}^{\prime}\left(Q_{i}\right) \geq p\right\}} m_{i}\left(p-c_{i}\right)\left[Q_{i}-\underline{S}(p)\right] \leq 0
$$

as $K>1$, which, given (37), implies

$$
\sum_{\left\{i: u_{i}^{\prime}\left(Q_{i}\right) \geq p\right\}} m_{i}\left(p-c_{i}\right)\left[q_{i}^{k}-\underline{s}^{k}(p)\right]=0, \quad k=1, \ldots, K .
$$

Hence each market maker $k$ makes zero expected profit on trades in excess of $\underline{s}^{k}(p)$ taking place at marginal price $p$.

Step 2. Now suppose, to the contrary, that trade also takes place at a marginal price strictly less than $p$ and let $p^{\prime}$ be the highest such price. That is, $\bar{s}^{k}\left(p^{\prime}\right)=\underline{s}^{k}(p)$ for all $k, p^{\prime} \equiv \partial^{-} T\left(\bar{S}\left(p^{\prime}\right)\right)$, and $\underline{S}(p)=\bar{S}\left(p^{\prime}\right)>\underline{S}\left(p^{\prime}\right)$. We claim that type $j \equiv \min \left\{i: Q_{i} \geq \bar{S}\left(p^{\prime}\right)\right\}$ has a unique best response that consists of purchasing $\bar{s}^{k}\left(p^{\prime}\right)$ from each market maker $k$, thus exactly exhausting aggregate supply $\bar{S}\left(p^{\prime}\right)$ at marginal price $p^{\prime}$. By definition of $j, Q_{j-1}<\bar{S}\left(p^{\prime}\right)$, with $Q_{0}=0$ by convention, $q_{j-1}^{k} \leq \bar{s}\left(p^{\prime}\right) \leq q_{j}^{k}$ for all $k$, with $q_{0}^{k}=0$ for all $k$ by convention, and $q_{j-1}^{k}<\bar{s}\left(p^{\prime}\right)$ for at least one $k$. To prove the claim, we show that $p_{j}=p^{\prime}$, where $p_{j}$ is the Lagrange multiplier associated to the solution of (2); see Step 0 of the proof of Lemma 3 in the Supplemental Material. Notice first that $p_{j} \geq p^{\prime}$ as $Q_{j} \geq \bar{S}\left(p^{\prime}\right)$. Suppose then that $p_{j}>p^{\prime}$ and fix a $k$ such that $q_{j-1}^{k}<\bar{s}^{k}\left(p^{\prime}\right)$. Then market maker $k$ could deviate to a tariff coinciding with $t^{k}$ up to $q_{j-1}^{k}$ and offering to sell any quantity between $q_{j-1}^{k}$ and $q_{j}^{k}$ at marginal price $p_{j}$, as well as any quantity between $q_{j}^{k}$ and $q_{I}^{k}$ at marginal price $p$. A best response for the insider consists of purchasing the same quantities $q_{i}^{k}$ from market maker $k$ as when he posts the tariff $t^{k}$, overall preserving nondecreasing quantities and yielding him a strictly higher expected profit than his 
equilibrium expected profit. We can then apply Lemma 3 to obtain a contradiction. The claim follows.

Step 3. Defining $j$ as in Step 2, observe that, by (38), we have

$$
\sum_{i \geq j} m_{i}\left(p-c_{i}\right)\left[q_{i}^{k}-\underline{s}^{k}(p)\right]=0, \quad k=1, \ldots, K,
$$

because $q_{i}^{k}=\bar{s}^{k}\left(p^{\prime}\right)=\underline{s}^{k}(p)$ for all $k$ and $i \geq j$ such that $u_{i}^{\prime}\left(Q_{i}\right)<p$. Now as $Q_{j-1}<\bar{S}\left(p^{\prime}\right)$, there exists a market maker $k$ such that

$$
\underline{q}^{k} \equiv \max \left\{\underline{s}^{k}\left(p^{\prime}\right), q_{j-1}^{k}\right\}<\bar{s}^{k}\left(p^{\prime}\right) .
$$

According to Step 2, type $j$ has a unique best response, in which she purchases $\bar{s}^{k}\left(p^{\prime}\right)$ from market maker $k$. Hence $z_{j}^{-k}\left(\bar{s}^{k}\left(p^{\prime}\right), t^{k}\left(\bar{s}^{k}\left(p^{\prime}\right)\right)\right)>\max \left\{z_{j}^{-k}\left(q, t^{k}(q)\right): q \leq \underline{q}^{k}\right\}$, so that, by continuity, there exists some strictly positive $\varepsilon$ such that

$$
z_{j}^{-k}\left(\bar{s}^{k}\left(p^{\prime}\right), t^{k}\left(\bar{s}^{k}\left(p^{\prime}\right)\right)+\varepsilon\left[\bar{s}^{k}\left(p^{\prime}\right)-\underline{q}^{k}\right]\right)>z_{j}^{-k}\left(q, t^{k}(q)\right), \quad q \leq \underline{q}^{k} .
$$

Let us then fix an arbitrary

$$
\bar{q}^{k} \in \arg \max \left\{z_{j}^{-k}\left(q, t^{k}\left(\underline{q}^{k}\right)+\left(p^{\prime}+\varepsilon\right)\left(q-\underline{q}^{k}\right)\right): q \in\left[\underline{q}^{k}, \bar{s}^{k}\left(p^{\prime}\right)\right]\right\} .
$$

As $t^{k}\left(\bar{s}^{k}\left(p^{\prime}\right)\right)=t^{k}\left(\underline{q}^{k}\right)+p^{\prime}\left[\bar{s}^{k}\left(p^{\prime}\right)-\underline{q}^{k}\right],(40)$ and (41) imply $\bar{q}^{k}>\underline{q}^{k}$. Market maker $k$ could thus deviate to a tariff coinciding with $t^{k}$ up to $\underline{q}^{k}$ and offering to sell any quantity between $\underline{q}^{k}$ and $\bar{q}^{k}$ at marginal price $p^{\prime}+\varepsilon$. A best response for the insider consists of purchasing $q_{i}^{k}$ or $\bar{q}^{k}$ from market maker $k$ depending on whether $i<j$ or $i \geq j$, overall preserving nondecreasing quantities. We can thus apply Lemma 3 to obtain

$$
\begin{aligned}
\sum_{i \geq j} m_{i}\left(p^{\prime}+\varepsilon-c_{i}\right)\left(\bar{q}^{k}-\underline{q}^{k}\right) & \leq \sum_{i \geq j} m_{i}\left\{\left(p^{\prime}-c_{i}\right)\left[\bar{s}^{k}\left(p^{\prime}\right)-\underline{q}^{k}\right]+\left(p-c_{i}\right)\left[q_{i}^{k}-\underline{s}^{k}(p)\right]\right\} \\
& =\sum_{i \geq j} m_{i}\left(p^{\prime}-c_{i}\right)\left[\bar{s}^{k}\left(p^{\prime}\right)-\underline{q}^{k}\right]
\end{aligned}
$$

where the equality follows from (39). Rearranging, we obtain

$$
\sum_{i \geq j} m_{i}\left(p^{\prime}-c_{i}\right)\left[\bar{s}^{k}\left(p^{\prime}\right)-\bar{q}^{k}\right] \geq \sum_{i \geq j} m_{i} \varepsilon\left(\bar{q}^{k}-\underline{q}^{k}\right)>0
$$

because $\bar{q}^{k}>\underline{q}^{k}$. As $\bar{s}^{k}\left(p^{\prime}\right) \geq \bar{q}^{k}$ by (41), we thus have shown

$$
\sum_{i \geq j} m_{i}\left(p^{\prime}-c_{i}\right)>0
$$

Finally, any market maker $k$ could also attract all trades at marginal price $p^{\prime}$ by deviating to a tariff coinciding with $t^{k}$ up to $\underline{s}^{k}(p)$ and offering to sell any quantity between $\underline{s}^{k}\left(p^{\prime}\right)$ and $\underline{s}^{k}\left(p^{\prime}\right)+\bar{S}\left(p^{\prime}\right)-\underline{S}\left(p^{\prime}\right)$ at marginal price $p^{\prime}$. A best response for the insider consists 
of purchasing $q_{i}^{k}$ or $\underline{s}^{k}\left(p^{\prime}\right)+\bar{S}\left(p^{\prime}\right)-\underline{S}\left(p^{\prime}\right)$ from market maker $k$ depending on whether $i<j$ or $i \geq j$, overall preserving nondecreasing quantities. We can thus apply Lemma 3 to obtain

$$
\begin{aligned}
& \sum_{i \geq j} m_{i}\left(p^{\prime}-c_{i}\right)\left[\bar{S}\left(p^{\prime}\right)-\underline{S}\left(p^{\prime}\right)\right] \\
& \quad \leq \sum_{i \geq j} m_{i}\left(p^{\prime}-c_{i}\right)\left[\bar{s}^{k}\left(p^{\prime}\right)-\underline{s}^{k}\left(p^{\prime}\right)\right]+\sum_{i \geq j} m_{i}\left(p-c_{i}\right)\left[q_{i}^{k}-\underline{s}^{k}(p)\right], \\
& \quad=\sum_{i \geq j} m_{i}\left(p^{\prime}-c_{i}\right)\left[\bar{s}^{k}\left(p^{\prime}\right)-\underline{s}^{k}\left(p^{\prime}\right)\right], \quad k=1, \ldots, K,
\end{aligned}
$$

again taking advantage of (39). Summing these inequalities over $k$ in turn yields

$$
\sum_{i \geq j} m_{i}\left(p^{\prime}-c_{i}\right)\left[\bar{S}\left(p^{\prime}\right)-\underline{S}\left(p^{\prime}\right)\right] \leq 0
$$

as $K>1$, which, given $\bar{S}\left(p^{\prime}\right)>\underline{S}\left(p^{\prime}\right)$, contradicts (42). It follows that no trade can take place at a marginal price strictly less than $p$.

Step 4. From Step 3, all trades must take place at price $p$ and the insider faces an aggregate tariff $T$ that is linear with slope $p$ up to $\bar{S}(p)$. To complete the proof, suppose, to the contrary, that $\bar{S}(p)>0$ and $Q_{i}=\bar{S}(p)$ for some type $i$ who thus exactly exhausts aggregate supply $\bar{S}(p)$ at price $p$; denote by $j$ the lowest such type. Then at least one market maker $k$ must be indispensable for type $j$ to reach her equilibrium utility. Arguing as in Step 3, market maker $k$ could slightly raise the price $p$ on an interval $\left[q^{k}, \bar{q}^{k}\right]$, thereby earning a strictly positive expected profit, in contradiction to (38). Hence the result.

Proof of Theorem 3. The proof has two parts.

Necessity. We first show that conditions (20) are necessary for an equilibrium with convex tariffs. The proof consists of two steps.

Step 1 . Observe first that according to Proposition 5, we can with no loss of generality focus on an equilibrium with nondecreasing individual quantities. Let us then fix such an equilibrium and let $p$ be the equilibrium price, which must belong to $\partial c_{I}\left(D_{I}(p) / K\right)$ by Theorems 1 and 2 . For each $k$, let $\bar{S}^{-k}(p) \equiv \bar{S}(p)-\bar{s}^{k}(p)$ be the aggregate supply at price $p$ of the market makers other than $k$. Now suppose $\bar{S}(p)>0$ and $D_{I}(p) \geq q_{I}^{k}+$ $\bar{S}^{-k}(p)$ for all $k$. Summing these inequalities over $k$, we obtain $D_{I}(p) \geq \bar{S}(p)>0$ as $K>1$, which contradicts the final statements of Propositions 1 and 2. Hence, if $\bar{S}(p)>0$, there exists $k$ such that

$$
D_{I}(p)-q_{I}^{k}<\bar{S}^{-k}(p) .
$$

Moreover, because the equilibrium has nondecreasing individual quantities and because each type $i$ purchases $D_{i}(p)$ in the aggregate, we have, for each $i$,

$$
D_{i}(p)-q_{i}^{k}=\sum_{l \neq k} q_{i}^{l} \leq \sum_{l \neq k} q_{I}^{l}=D_{I}(p)-q_{I}^{k} .
$$


Therefore, we have shown that if $\bar{S}(p)>0$, there exists $k$ and some strictly positive $\varepsilon$ such that, for each $i$,

$$
D_{i}(p)-q_{i}^{k}+\varepsilon \leq \bar{S}^{-k}(p) .
$$

Step 2. Now, suppose, to the contrary, that $\bar{c}_{i}(p)<\tau_{i}(0,0)$ for some type $i<i^{*}$. Any market maker $k$ could deviate by placing a limit order with price $p^{\prime} \in\left(\bar{c}_{i}(p), \tau_{i}(0,0)\right)$ and maximum quantity $\bar{q}$ for some small $\bar{q}$, together with a limit order with price $p$ and maximum quantity $\max \left\{q_{I}^{k}-\bar{q}, 0\right\}$. This offer is a pair of limit orders and, therefore, is equivalent to a convex tariff. According to Lemmas 2 and 3, market maker $k$ can break ties in his favor as long as he sticks to nondecreasing quantities. For $\bar{q}$ small enough, the first limit order attracts type $i$ as well as types $j>i$ by Property SC- $z$, and any such type exactly purchases $\bar{q}$ along this limit order. We now evaluate the contribution of each type to market maker $k$ 's expected profit following his deviation.

Consider first types $j=i, \ldots, i^{*}-1$. By construction, they purchase $\bar{q}$ at price $p^{\prime}$ from market maker $k$. Moreover, they do not want to make additional trades at price $p$ : indeed, by Property $\mathrm{P}$, their marginal rate of substitution computed at their final trade $\left(\bar{q}, p^{\prime} \bar{q}\right)$ along the first limit order is at most equal to $\tau_{i}(0,0)$, which is itself at most equal to $p$. Hence their contribution to market maker $k$ 's expected profit is

$$
\sum_{i^{*}>j \geq i} m_{j}\left[p^{\prime} \bar{q}-c_{j}(\bar{q})\right]=\sum_{i^{*}>j \geq i} m_{j}\left[p^{\prime}-\partial^{+} c_{j}(0)\right] \bar{q}+o(\bar{q})
$$

for $\bar{q}$ small enough.

Consider next types $j<i$. They may also be willing to purchase positive quantities at price $p^{\prime}$-though not at price $p$-from market maker $k$, but unlike for types $j=i, \ldots, i^{*}-$ 1 , we cannot precisely estimate these purchases. However, Assumption SC- $v$ implies that for any such type, we have $p^{\prime}>\bar{c}_{i}(p) \geq \partial^{+} c_{j}(0)$. Hence, their contribution to market maker $k$ 's expected profit is nonnegative for $\bar{q}$ small enough.

Consider finally types $j \geq i^{*}$. By Assumption I- $U$, once they have purchased $\bar{q}$ at price $p^{\prime}$ from market maker $k$, their new demands at price $p$ are finite. Two cases may arise. If $\bar{S}(p)=0$, then, by Theorems 1 and 2, for all these types $D_{j}(p)=0$ and thus $\tau_{j}(0,0) \leq p$; hence, by Property $\mathrm{P}$ again, they do not want to make additional trades at price $p$. If $\bar{S}(p)>0$, then by Berge's maximum theorem (Aliprantis and Border 2006, Theorem 17.31), we can choose $\bar{q}$ small enough so that their new demands at price $p$ are within $\varepsilon$ of $D_{j}(p)$, and, by Step 1, we can select $k$ such that (43) holds. A best response for types $j \geq i^{*}$ then consists of purchasing $\max \left\{q_{j}^{k}, \bar{q}\right\}$ from market maker $k$, overall preserving nondecreasing quantities; indeed, by (43), the market makers other than $k$ supply an aggregate quantity $\bar{S}^{-k}(p)$ that is high enough to cover the rest of their new demands at price $p$. Hence, their contribution to market maker $k$ 's expected profit is

$$
\sum_{j \geq i^{*}} m_{j}\left[p^{\prime} \bar{q}+p \max \left\{q_{j}^{k}-\bar{q}, 0\right\}-c_{j}\left(\max \left\{q_{j}^{k}, \bar{q}\right\}\right)\right]
$$

or, equivalently,

$$
v^{k}+\left(p^{\prime}-p\right) \sum_{j \geq i^{*}} m_{j} \bar{q}+\sum_{j \geq i^{*}} m_{j}\left\{p\left[\max \left\{q_{j}^{k}, \bar{q}\right\}-q_{j}^{k}\right]-\left[c_{j}\left(\max \left\{q_{j}^{k}, \bar{q}\right\}\right)-c_{j}\left(q_{j}^{k}\right)\right]\right\},
$$


where $v^{k}$ is the equilibrium expected profit of market maker $k$ :

$$
v^{k} \equiv \sum_{j \geq i^{*}} m_{j}\left[p q_{j}^{k}-c_{j}\left(q_{j}^{k}\right)\right]
$$

We now give a lower bound for the last term of (45). For each $j$, select $\gamma_{j} \in \partial c_{j}\left(\max \left\{q_{j}^{k}, \bar{q}\right\}\right)$. Because $q_{j}^{k}$ is nondecreasing in $j$, we can assume that $\gamma_{j}$ is nondecreasing in $j$. Then

$$
\begin{aligned}
& \sum_{j \geq i^{*}} m_{j}\left\{p\left[\max \left\{q_{j}^{k}, \bar{q}\right\}-q_{j}^{k}\right]-\left[c_{j}\left(\max \left\{q_{j}^{k}, \bar{q}\right\}\right)-c_{j}\left(q_{j}^{k}\right)\right]\right\} \\
& \quad \geq \sum_{j \geq i^{*}} m_{j}\left(p-\gamma_{j}\right) \max \left\{\bar{q}-q_{j}^{k}, 0\right\} \\
& \quad \geq\left(\sum_{j \geq i^{*}} m_{j}\right)^{-1}\left(\sum_{j \geq i^{*}} m_{j}\left(p-\gamma_{j}\right)\right)\left(\sum_{j \geq i^{*}} m_{j} \max \left\{\bar{q}-q_{j}^{k}, 0\right\}\right),
\end{aligned}
$$

where the first inequality follows from the convexity of $c_{j}$ and the second inequality follows from Chebyshev's sum inequality (Hardy et al. 1934, Chapter II, Section 17), taking advantage of the fact that $\gamma_{j}$ and $q_{j}^{k}$ are nondecreasing in $j$. In the linear-cost case, $p=c_{I}=\gamma_{j}$ in equilibrium, so that the right-hand side of (46) is zero. In the convex-cost case, $i^{*}=I$, and two cases may arise: Either $q_{I}^{k}>0$, so then the righthand side of (46) is zero for $\bar{q}$ small enough, or $q_{I}^{k}=0$, so that $p \geq \partial c^{+}(0)$. Then $\left(p-\gamma_{I}\right) \bar{q} \geq\left[\partial c^{+}(0)-\partial c^{-}(\bar{q})\right] \bar{q}=o(\bar{q})$ for $\bar{q}$ small enough. In any case, we obtain from (45) that the contribution of types $j \geq i^{*}$ to market maker $k$ 's expected profit is at least

$$
v^{k}+\left(p^{\prime}-p\right) \sum_{j \geq i^{*}} m_{j} \bar{q}+o(\bar{q})
$$

for $\bar{q}$ small enough.

To conclude, summing (44) and (47) and taking advantage of (19) yields that market maker $k$ 's expected profit from deviating is at least

$$
v^{k}+\left[p^{\prime}-\bar{c}_{i}(p)\right] \sum_{j \geq i} m_{j} \bar{q}+o(\bar{q}),
$$

which is strictly higher than $v^{k}$ for $\bar{q}$ small enough as $p^{\prime}>\bar{c}_{i}(p)$. This shows that conditions (20) are necessary for an equilibrium with convex tariffs.

Sufficiency. We next show that conditions (20) are sufficient for an equilibrium in which each market maker posts the linear tariff (21). As a preliminary remark, observe that for each $k$, the family of functions $z_{i}^{-k}$ satisfies Property SC- $z$. Hence, we can assume that the insider purchases nondecreasing quantities from market maker $k$ following any deviation on his part. Focusing on the insider's downward local constraints (7), we obtain that market maker $k$ 's expected profit from deviating is bounded above by $V^{k}\left(t^{-k}\right)$, as defined by (8). There remains to show that $V^{k}\left(t^{-k}\right)$ cannot exceed the expected profit $v^{k}$ earned by market maker $k$ in the candidate equilibrium. The proof consists of three steps. 
Step 1. We first show that in computing $V^{k}\left(t^{-k}\right)$, we can with no loss of generality focus on menus with nonnegative transfers. Indeed, let $\mu \equiv\left\{\left(q_{i}, t_{i}\right): i=0, \ldots, I\right\}$ be a menu that satisfies all the constraints in the problem (8) that defines $V^{k}\left(t^{-k}\right)$ and is such that at least one type makes a strictly negative transfer; denote by $i$ the lowest such type. We can then build a new menu $\mu^{\prime}$ that differs from $\mu$ only in allocating $\left(q_{i-1}, t_{i-1}\right)$ to type $i$. We claim that $\mu^{\prime}$ satisfies all the constraints in (8). First, because $\mu$ has nondecreasing quantities, so does $\mu^{\prime}$. Second, the downward local constraint of type $i$ is now an identity. Third, the downward local constraint of type $i+1$, if such a type exists, now is written as $z_{i+1}^{-k}\left(q_{i+1}, t_{i+1}\right) \geq z_{i+1}^{-k}\left(q_{i-1}, t_{i-1}\right)$, which holds by Property SC- $z$ as $\mu$ satisfies $q_{i} \geq q_{i-1}, z_{i+1}^{-k}\left(q_{i+1}, t_{i+1}\right) \geq z_{i+1}^{-k}\left(q_{i}, t_{i}\right)$, and $z_{i}^{-k}\left(q_{i}, t_{i}\right) \geq z_{i}^{-k}\left(q_{i-1}, t_{i-1}\right)$. Thus $\mu^{\prime}$ satisfies all the constraints in (8), as claimed. The resulting variation in market maker $k$ 's expected profit is

$$
\left[t_{i-1}-c_{i}\left(q_{i-1}\right)\right]-\left[t_{i}-c_{i}\left(q_{i}\right)\right]=t_{i-1}-t_{i}+c_{i}\left(q_{i}\right)-c_{i}\left(q_{i-1}\right)
$$

up to multiplication by $m_{i}$, and is strictly positive because $q_{i} \geq q_{i-1}$ and $t_{i-1} \geq 0>t_{i}$ by definition of $i$. It follows that $\mu$ cannot be a solution to (8).

Step 2. Given the equilibrium strategies specified in Theorem 3 , following a deviation by market maker $k$, each type $i$ can, in addition to $\left(q_{i}, t_{i}\right)$, purchase some quantity $Q_{i}^{-k} \leq$ $D_{i}(p)$ at price $p$ from market makers other than $k$. Notice that we must have $U_{i}\left(q_{i}, t_{i}\right) \geq$ $U_{i}(0,0)$, for, otherwise, type $i$ would be strictly better off not trading with market maker $k$ and purchasing her demand $D_{i}(p)$ at price $p$ from market makers other than $k$. Now using the convexity of cost functions, market maker $k$ 's expected profit from offering a menu satisfying the constraints in (8) can be bounded above as

$$
\sum_{i} m_{i}\left[t_{i}-c_{i}\left(q_{i}\right)\right] \leq \sum_{i^{*}>i} m_{i}\left[t_{i}-\partial^{+} c_{i}(0) q_{i}\right]+\sum_{i \geq i^{*}} m_{i}\left(t_{i}-p q_{i}\right)+\sum_{i \geq i^{*}} m_{i}\left[p q_{i}-c_{i}\left(q_{i}\right)\right] .
$$

Because, in the candidate equilibrium, each market maker sells an element of his competitive supply at price $p$ to types $i \geq i^{*}$, the third term on the right-hand side of (48) is bounded above by the candidate-equilibrium expected profit:

$$
\sum_{i \geq i^{*}} m_{i}\left[p q_{i}-c_{i}\left(q_{i}\right)\right] \leq v^{k}
$$

As for the two remaining terms, a summation by parts, taking advantage of (19), yields

$$
\sum_{i^{*}>i} m_{i}\left[t_{i}-\partial^{+} c_{i}(0) q_{i}\right]+\sum_{i \geq i^{*}} m_{i}\left(t_{i}-p q_{i}\right)=\sum_{i}\left(\sum_{j \geq i} m_{j}\right)\left[t_{i}-t_{i-1}-\bar{c}_{i}(p)\left(q_{i}-q_{i-1}\right)\right] .
$$

In light of (48)-(50), we only need to check that

$$
t_{i}-t_{i-1} \leq \bar{c}_{i}(p)\left(q_{i}-q_{i-1}\right), \quad i=1, \ldots, I .
$$

We turn to this task in the last step of the proof.

Step 3. Consider first any type $i<i^{*}$. If $i>1$, we know that $U_{i-1}\left(q_{i-1}, t_{i-1}\right) \geq$ $U_{i-1}(0,0)$; therefore, by Assumption SC- $U$, we obtain $U_{i}\left(q_{i-1}, t_{i-1}\right) \geq U_{i}(0,0)$, which 
also trivially holds when $i=1$. We also know from Step 1 that $t_{i-1}$ is nonnegative; therefore, by Property $\mathrm{P}$ and condition (20), we obtain $\tau_{i}\left(q_{i-1}, t_{i-1}\right) \leq \bar{c}_{i}(p)$. Notice also that $\bar{c}_{i}(p) \leq p$ as $\partial^{+} c_{j}(0) \leq p \in \partial c_{I}\left(D_{I}(p) / K\right)$ for all $j<i^{*}$ by Assumption SC- $v$. Hence, for type $i$ to agree to trade $\left(q_{i}-q_{i-1}, t_{i}-t_{i-1}\right)$ and $\left(Q_{i}^{-k}, p Q_{i}^{-k}\right)$ on top of $\left(q_{i-1}, t_{i-1}\right),(51)$ must hold.

Consider next any type $i \geq i^{*}$ for which $\bar{c}_{i}(p)=p$ by (19). Two cases may arise: Either $q_{i}-q_{i-1} \leq D_{i}(p)$, so then (51) follows from the fact that the quantity $q_{i}-q_{i-1}$ is supplied at price $p$ by the market makers other than $k$, or $q_{i}-q_{i-1}>D_{i}(p)$. We then need the following generalization of Property $\mathrm{P}$, the proof of which follows along the same lines.

Property $\mathrm{P}^{\prime}$. For all $i, Q \leq Q^{\prime}$, and $T^{\prime} \geq T \geq 0$,

$$
U_{i}\left(Q^{\prime}, T^{\prime}\right) \geq U_{i}(Q, T) \quad \text { implies } \quad \tau_{i}\left(Q^{\prime}, T^{\prime}\right) \leq \tau_{i}(Q, T) .
$$

Now suppose, to the contrary, that $q_{i}-q_{i-1}>D_{i}(p)$ and (51) does not hold, so that $t_{i}-t_{i-1}>p\left(q_{i}-q_{i-1}\right)$. We must have

$$
U_{i}\left(q_{i-1}+D_{i}(p), t_{i-1}+p D_{i}(p)\right) \geq U_{i}\left(D_{i}(p), p D_{i}(p)\right)
$$

and

$$
\tau_{i}\left(q_{i-1}+D_{i}(p), t_{i-1}+p D_{i}(p)\right)>p,
$$

for, otherwise, type $i$ would not agree to trade $\left(q_{i}-q_{i-1}-D_{i}(p), t_{i}-t_{i-1}-p D_{i}(p)\right)$ and $\left(Q_{i}^{-k}, p Q_{i}^{-k}\right)$ on top of $\left(q_{i-1}+D_{i}(p), t_{i-1}+p D_{i}(p)\right)$. However, because $t_{i-1}$ is nonnegative by Step 1, Property $\mathrm{P}^{\prime}$ and (52) imply

$$
\tau_{i}\left(q_{i-1}+D_{i}(p), t_{i-1}+p D_{i}(p)\right) \leq \tau_{i}\left(D_{i}(p), p D_{i}(p)\right) \leq p,
$$

which contradicts (53). Hence the result.

\section{REFERENCES}

Akerlof, George A. (1970), “The market for "lemons”: Quality uncertainty and the market mechanism.” Quarterly Journal of Economics, 84, 488-500. [298, 317, 328]

Aliprantis, Charalambos D. and Kim C. Border (2006), Infinite Dimensional Analysis: A Hitchhiker's Guide, third edition. Springer, Berlin. [306, 337]

Allen, Beth and Martin F. Hellwig (1986), "Price-setting firms and the oligopolistic foundations of perfect competition.” American Economic Review, 76, 387-392. [333]

Attar, Andrea, Thomas Mariotti, and François Salanié (2011), "Nonexclusive competition in the market for lemons.” Econometrica, 79, 1869-1918. [305, 307]

Attar, Andrea, Thomas Mariotti, and François Salanié (2014), "Nonexclusive competition under adverse selection.” Theoretical Economics, 9, 1-40. [298, 299, 301, 302, 305, 326] 
Attar, Andrea, Thomas Mariotti, and François Salanié (2016), "Multiple contracting in insurance markets.” Working Paper 14-532, Toulouse School of Economics. [327]

Attar, Andrea, Thomas Mariotti, and François Salanié (2017), "Entry proofness and market breakdown under adverse selection.” Working Paper 17-788, Toulouse School of Economics. [322, 327]

Back, Kerry and Shmuel Baruch (2013), "Strategic liquidity provision in limit order markets.” Econometrica, 81, 363-392. [298, 299, 300, 302, 303, 304, 305, 313, 325, 326]

Back, Kerry and Jaime F. Zender (1993), "Auctions of divisible goods: On the rationale for the treasury experiment.” Review of Financial Studies, 6, 733-764. [301]

Baruch, Shmuel and Lawrence R. Glosten (2017), "Tail expectation, imperfect competition, and the phenomenon of flickering quotes in limit order book markets." Unpublished paper, David Eccles School of Business, University of Utah. [325]

Biais, Bruno, Thierry Foucault, and François Salanié (1998), "Floors, dealer markets and limit order markets.” Journal of Financial Markets, 1, 253-284. [306]

Biais, Bruno, David Martimort, and Jean-Charles Rochet (2000), "Competing mechanisms in a common value environment." Econometrica, 68, 799-837. [298, 299, 300, 301, 302, 304, 305, 307, 309, 310, 312, 325, 326, 329, 330, 332, 333]

Biais, Bruno, David Martimort, and Jean-Charles Rochet (2013), "Corrigendum to "Competing mechanisms in a common value environment”." Econometrica, 81, 393-406. [302, 303]

Borch, Karl (1962), “Equilibrium in a reinsurance market.” Econometrica, 30, 424-444. [320]

Carmona, Guilherme and José Fajardo (2009), "Existence of equilibrium in common agency games with adverse selection." Games and Economic Behavior, 66, 749-760. [333]

Dennert, Jürgen (1993), “Price competition between market makers.” Review of Economic Studies, 60, 735-751. [325]

Dubey, Pradeep (1982), "Price-quantity strategic market games.” Econometrica, 50, 111126. [306]

Glosten, Lawrence R. (1989), "Insider trading, liquidity, and the role of the monopolist specialist.” Journal of Business, 62, 211-235. [307, 325]

Glosten, Lawrence R. (1994), “Is the electronic open limit order book inevitable?” Journal of Finance, 49, 1127-1161. [301, 302, 304, 315, 316, 326, 327, 333]

Glosten, Lawrence R. (1998), “Competition, design of exchanges and welfare.” Unpublished paper, Columbia Business School. [302]

Glosten, Lawrence R. and Paul R. Milgrom (1985), "Bid, ask and transaction prices in a specialist market with heterogeneously informed traders." Journal of Financial Economics, 14, 71-100. [304] 
Grossman, Sanford J. (1981), "Nash equilibrium and the industrial organization of markets with large fixed costs.” Econometrica, 49, 1149-1172. [301]

Han, Seungjin (2006), "Menu theorems for bilateral contracting." Journal of Economic Theory, 131, 157-178. [308]

Hardy, Godfrey H., John E. Littlewood, and George Pólya (1934), Inequalities. Cambridge University Press, Cambridge, UK. [338]

Hellwig, Martin F. (1988), "A note on the specification of interfirm communication in insurance markets with adverse selection." Journal of Economic Theory, 46, 154-163. $[302,327]$

Hendren, Nathaniel (2014), "Unravelling vs unravelling: A memo on competitive equilibriums and trade in insurance markets." Geneva Risk and Insurance Review, 39, 176183. [316]

Ho, Thomas S. Y. and Hans R. Stoll (1981), "Optimal dealer pricing under transactions and return uncertainty." Journal of Financial Economics, 9, 47-73. [304, 317, 319]

Ho, Thomas S. Y. and Hans R. Stoll (1983), "The dynamics of dealer markets under competition." Journal of Finance, 38, 1053-1074. [304, 317, 319]

Jaynes, Gerald D. (1978), "Equilibria in monopolistically competitive insurance markets." Journal of Economic Theory, 19, 394-422. [302, 327]

Klemperer, Paul D. and Margaret A. Meyer (1989), "Supply function equilibria in oligopoly under uncertainty." Econometrica, 57, 1243-1277. [301]

Kyle, Albert S. (1985), “Continuous auctions and insider trading." Econometrica, 53, 1315-1335. [304]

Kyle, Albert S. (1989), "Informed speculation with imperfect competition." Review of Economic Studies, 56, 317-355. [301]

Milgrom, Paul and Chris Shannon (1994), "Monotone comparative statics." Econometrica, 62, 157-180. [303]

Parlour, Christine A. and Duane J. Seppi (2008), "Limit order markets: A survey." In Handbook of Financial Intermediation and Banking (Anjan Thakor and Arnoud Boot, eds.), 63-96, Elsevier, Amsterdam. [301]

Pauly, Mark V. (1974), "Overinsurance and public provision of insurance: The roles of moral hazard and adverse selection." Quarterly Journal of Economics, 88, 44-62. [302, 308]

Riley, John G. (1985), “Competition with hidden knowledge.” Journal of Political Economy, 93, 958-976. [302]

Riley, John G. (2001), “Silver signals: Twenty-five years of screening and signaling." Journal of Economic Literature, 39, 432-478. [302] 
Rockafellar, R. Tyrrell (1970), Convex Analysis. Princeton University Press, Princeton, New Jersey. [305, 306]

Roll, Richard (1984), "A simple implicit measure of the effective bid-ask spread in an efficient market." Journal of Finance, 39, 1127-1139. [304, 305, 317, 319]

Rothschild, Michael and Joseph E. Stiglitz (1976), "Equilibrium in competitive insurance markets: An essay on the economics of imperfect information." Quarterly Journal of Economics, 90, 629-649. [302, 317]

Stoll, Hans R. (1978), “The supply of dealer services in securities markets.” Journal of Finance, 33, 1133-1151. [304, 317, 319]

Vives, Xavier (2011), "Strategic supply function competition with private information.” Econometrica, 79, 1919-1966. [301]

Wilson, Robert (1979), “Auctions of shares.” Quarterly Journal of Economics, 93, 675-689. [301]

Co-editor George J. Mailath handled this manuscript.

Manuscript received 29 November, 2016; final version accepted 18 July, 2018; available online 25 July, 2018. 